\title{
1 Kinetics and correlates of the neutralizing antibody response to SARS-CoV-2
}

2 Kanika Vanshylla ${ }^{1}$, Veronica Di Cristanziano ${ }^{1,2}$, Franziska Kleipass ${ }^{1}$, Felix Dewald ${ }^{1}$, Philipp

3 Schommers ${ }^{1,2,3}$, Lutz Gieselmann ${ }^{1,2}$, Henning Gruell ${ }^{1,2}$, Maike Schlotz ${ }^{1}$, Meryem S

4 Ercanoglu ${ }^{1}$, Ricarda Stumpf ${ }^{1}$, Petra Mayer $^{1}$, Eva Heger $^{1}$, Wibke Johannis ${ }^{4}$, Carola Horn ${ }^{3}$,

5 Isabelle Suárez ${ }^{2,3}$, Norma Jung ${ }^{3}$, Susanne Salomon ${ }^{1}$, Kirsten Alexandra Eberhardt ${ }^{5}$, Gerd

6 Fätkenheuer ${ }^{2,3}$, Nico Pfeifer ${ }^{6,7,8}$, Ralf Eggeling ${ }^{6}$, Max Augustin $^{3}$, Clara Lehmann ${ }^{2,3,9}$, Florian

$7 \quad$ Klein $^{1,2,9}$,

$8{ }^{1}$ Institute of Virology, Faculty of Medicine and University Hospital of Cologne, University of Cologne,

950931 Cologne, Germany

$10 \quad{ }^{2}$ German Center for Infection Research, Partner Site Bonn-Cologne, 50931 Cologne, Germany

$11{ }^{3}$ Department I of Internal Medicine, Faculty of Medicine and University Hospital Cologne, University of 12 Cologne, 50937 Cologne, Germany

$13{ }^{4}$ Institute for Clinical Chemistry, Faculty of Medicine and University Hospital Cologne, University of 14 Cologne, Cologne, Germany

$15{ }^{5}$ Department of Tropical Medicine, Bernhard Nocht Institute for Tropical Medicine and Department of 16 Medicine, University Medical Center Hamburg-Eppendorf, 20359 Hamburg, Germany

$17{ }^{6}$ Methods in Medical Informatics, Department of Computer Science, University of Tuebingen, 72076

18 Tuebingen, Germany

$19{ }^{7}$ Faculty of Medicine, University of Tuebingen, 72076 Tuebingen, Germany

$20 \quad{ }^{8}$ German Center for Infection Research, Partner Site Tuebingen, 72076 Tuebingen, Germany

$21{ }^{9}$ Center for Molecular Medicine Cologne (CMMC), University of Cologne, 50931 Cologne, Germany 


\section{Abstract}

A detailed understanding of antibody-based SARS-CoV-2 immunity has critical implications for overcoming the COVID-19 pandemic and for informing on vaccination strategies. In this study, we evaluated the dynamics of the SARS-CoV-2 antibody response in a cohort of 963 recovered individuals over a period of 10 months. Investigating a total of 2,146 samples, we detected an initial SARS-CoV-2 antibody response in $94.4 \%$ of individuals, with $82 \%$ and $79 \%$ exhibiting serum and IgG neutralization, respectively. Approximately $3 \%$ of recovered patients demonstrated exceptional SARS-CoV-2 neutralizing activity, defining them as 'elite neutralizers'. These individuals also possessed effective cross-neutralizing IgG antibodies to SARS-CoV-1 without any known prior exposure to this virus. By applying multivariate statistical modeling, we found that sero-reactivity, age, time since disease onset, and fever are key factors predicting SARS-CoV-2 neutralizing activity in mild courses of COVID-19. Investigating longevity of the antibody response, we detected loss of anti-spike reactivity in $13 \%$ of individuals 10 months after infection. Moreover, neutralizing activity had an initial halflife of 6.7 weeks in serum versus 30.8 weeks in purified IgG samples indicating the presence of a more stable and long-term memory lgG B cell repertoire in the majority of individuals recovered from COVID-19. Our results demonstrate a broad spectrum of the initial SARS-

41 CoV-2 neutralizing antibody response depending on clinical characteristics, with antibodies being maintained in the majority of individuals for the first 10 months after mild course of COVID-19. 
Main

46

COVID-19 is caused by the severe acute respiratory syndrome coronavirus 2 (SARS-CoV-2), which was first identified in December $2019^{1,2}$. Since then, the virus has rapidly spread across the globe and caused more than 90 million proven infections and over 2 million deaths. Disease severity ranges from asymptomatic infection to symptoms like cough, fever, muscle pain, and diarrhea to severe courses of infection including pneumonia with severe respiratory distress and a high risk of death ${ }^{3-5}$. While the majority of infected individuals experience a mild course of disease, elderly or individuals with pre-existing conditions are at higher risk for severe courses of COVID-196. In symptomatic non-hospitalized cases, the

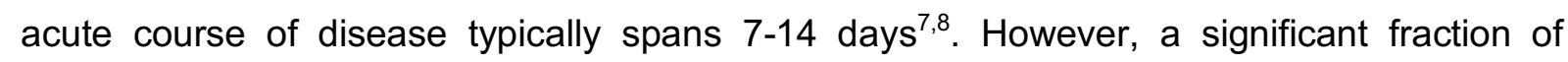
COVID-19 patients suffer long-lasting symptoms post recovery, so called 'post-COVID syndrome'9-11 (Augustin et al., submitted).

SARS-CoV-2 infects human cells by using the virus spike (S) protein ${ }^{12}$ for targeting the angiotensin converting enzyme-2 (ACE-2) receptor ${ }^{13}$. The S-protein carries dominant epitopes against which humoral B and $T$ cell responses are generated upon natural infection and vaccination ${ }^{14-18}$. Spike-specific $\lg \mathrm{M}, \lg \mathrm{A}$, and $\lg \mathrm{G}$ antibodies are detected early after infection ${ }^{19,20}$ and IgG antibody levels and lgG memory B cells can persist post infection ${ }^{21}$.

Neutralizing antibodies (NAbs) are powerful molecules that target viruses and block infection. Moreover, they can eliminate circulating viruses and infected cells by antibody-mediated effector functions ${ }^{22,23}$. As a result, NAbs are crucial to overcome infectious diseases and are an important correlate of protection ${ }^{24}$. For SARS-CoV-2, vaccine induced NAbs as well as purified IgGs from convalescent animals have been shown to protect non-human primates (NHPs) from infection in a SARS-CoV-2 challenge model ${ }^{25,26}$. Moreover, highly potent monoclonal NAbs have been isolated ${ }^{27-29}$ and are being used for treatment of COVID-19 in humans ${ }^{30,31}$.

Given the short time SARS-CoV-2 has been studied, information on long-term antibody dynamics are limited. Recent studies show that serum neutralizing activity is detectable 
72 within a week after onset of symptoms ${ }^{32,33}$ and can persist for the first months after

73 infection ${ }^{21,23,34}$. Moreover, studies with symptomatic and hospitalized individuals have shown

74 that more severe courses of disease result in a stronger SARS-CoV-2 neutralizing antibody

75 response ${ }^{14,35,36}$. While these studies provide important insights, a precise quantification of SARS-CoV-2 neutralizing activity and dynamics as well as clinical correlates of developing a protective antibody response are largely unknown.

In this study, we set out to provide a deeper understanding of the neutralizing antibody response to SARS-CoV-2. To this end, we determined neutralizing serum and IgG activity of 2,146 samples from a longitudinally monitored cohort of 963 individuals over time together

81 with detailed information on the course of disease and past medical history. We combined 82 statistical modeling to infer antibody decay rates after SARS-CoV-2 infection and built a 83 prediction model for evaluating how clinical or disease features correlate with NAb titers. 84 Finally, we performed longitudinal analyses to study anti-spike antibody levels as well as NAb titers for a time period of up to 10 months post SARS-CoV-2 infection. Our results inform on the kinetics, longevity and features affecting the antibody response to SARS-CoV-

87 2. They are critical to understand SARS-CoV-2 immunity and to guide non-pharmacological 88 interventions and vaccination strategies to overcome COVID-19 


\section{Results}

92 Establishing a cohort for investigating SARS-CoV-2 immunity

93 To investigate the development of SARS-CoV-2 immunity, we established a cohort of

94 COVID-19 patients who recently recovered from SARS-CoV-2 infection. Time since disease 95 onset was derived from self-reported symptom onset or date of positive naso-/oropharyngeal swab. In addition, each participant reported details on the course of infection, symptoms, and past medical history (Supplementary Table 1). Participants enrolled ranged from 18-79 years of age (median: 44 years) with a balanced distribution of males $(46.1 \%)$ and females $(53.9 \%)$. Disease severity included asymptomatic (4.6\%), mildly symptomatic

100 (91.69\%), and hospitalized individuals (2.6\%; Fig. 1, Supplementary Table 1). 23.4\% of 101 participants reported pre-existing conditions that have been described to influence COVID-19 102 outcomes $^{6}$.

103 Blood samples were collected from 963 individuals at study visit 1 (median 7.3 weeks post 104 disease onset) with follow up analyses at study visit 2 for 616 participants (median 18.8 weeks post disease onset), study visit 3 for 430 participants (median 30.1 weeks post disease onset), and study visit 4 for 137 participants (median 37.9 weeks post disease onset;

107 Fig. 1). Other participants were lost in follow-up or did not reach the respective study visit at the time of our analysis. Anti-spike IgG was quantified by ELISA and chemiluminescent

109 immunoassays (CLIA) and the NAb response to SARS-CoV-2 was analyzed using both

110 serum dilutions as well as purified IgG to precisely quantify neutralizing activity (Extended

111 Data Fig. 1). In total, 4,516 measurements were collected for visit 1 with another 1,867

112 subsequent measurements for visit 2-4 to determine the SARS-CoV-2 antibody response for

11310 months following infection. 


\section{Broad spectrum of the initial SARS-CoV-2 neutralizing antibody response}

118 NAb levels were quantified by testing serum and purified IgG from plasma/serum against 119 pseudovirus particles expressing the Wuhan01 spike protein (EPI_ESL406716). Serum 120 neutralization at study visit 1 was categorized based on titer into non- $\left(I_{50}<10\right)$, low$121 \quad\left(I D_{50}=10-25\right)$, average- $\left(I D_{50}=25-250\right)$, high- $\left(I D_{50}=250-2500\right)$, and elite-neutralizers

$122\left(\mathrm{ID}_{50}>2500\right.$; Fig. 2a). Mean serum $\mathrm{ID}_{50}$ titer was 111.3 with $17.7 \%$ of individuals that did not 123 reach $50 \%$ neutralization at the lowest serum dilution of $1: 10$. In addition, all samples were 124 purified for $\lg G$ and the neutralizing response was determined and categorized based on $\mathrm{IC}_{50}$ values into non- $\left(\mathrm{IC}_{50}>750 \mu \mathrm{g} / \mathrm{ml}\right)$, low- $\left(\mathrm{IC}_{50}=500-750 \mu \mathrm{g} / \mathrm{ml}\right)$, average- $\left(\mathrm{IC}_{50}=100-500\right.$ $\mu \mathrm{g} / \mathrm{ml})$, high- $\left(\mathrm{IC}_{50}=20-100 \mu \mathrm{g} / \mathrm{ml}\right)$, and elite-neutralization $\left(\mathrm{IC}_{50}<20 \mu \mathrm{g} / \mathrm{ml}\right.$; Fig. 2b). At study visit 1 , out of 963 participants, $10 \%, 44.8 \%$, and $20 \%$ demonstrated low, average, and high neutralization, respectively. $21 \%$ did not mount an IgG neutralizing response of an $\mathrm{IC}_{50}$ below $750 \mu \mathrm{g} / \mathrm{ml}$. $3.3 \%$ of individuals were classified as 'elite neutralizers' with $\mathrm{IC}_{50}$ values as low as $0.7 \mu \mathrm{g} / \mathrm{ml}$ detected in one individual at 8.6 weeks post disease onset. Combining serum and IgG measurements, $87.3 \%$ individuals showed detectable NAb activity at median 7.3 weeks after SARS-CoV-2 infection (Fig. 2c). The serum and IgG neutralization potency categorization matched for most individuals with a high correlation between serum ID $\mathrm{D}_{50}$ titers

134 and $\operatorname{lgG} \mathrm{IC}_{50}$ values (spearman $r=-0.72, p<0.0001$; Fig. $2 \mathrm{c}$ ). Moreover, only $5 \%$ samples 135 had only serum and no $\lg G$ neutralization indicating that $\lg G$ antibodies forms the dominant 136 NAb isotype in serum. To further determine the predictive value of IgG binding to the $S$ 137 protein for SARS-CoV-2 neutralization, we performed an S1-reactive ELISA (Euroimmun) on 138 all samples of visit $1.82 .8 \%$ and $70.2 \%$ of individuals possessed spike-reactive IgG (Fig. 2 d,

139 e) and IgA Abs, respectively (Fig. 2d and Extended Data Fig. 2a). Anti-spike IgG levels 140 were directly proportional to $\operatorname{lgG} N A b I C_{50}$ values (spearman $r=-0.62, p<0.0001$; Fig. 2f) 141 and IgG Ab levels better correlated with serum neutralization than IgA Ab levels (Extended 142 Data Fig. 2c, d). 
143 Finally, we determined the fraction of individuals lacking any detectable antibody response.

144 To this end, we combined the results of different IgG and IgA assays detecting binding to 145 SARS-CoV-2 S1, S1/S2, and $\mathrm{N}$ as well as three neutralization assays (Fig. $\mathbf{2} \mathbf{g}$ ). Out of the 146166 anti-S1-lgG negative $(12.7 \%)$ or equivocal $(4.6 \%)$ individuals, we found binding 147 antibodies in $62.0 \%$ in at least one of four assays and neutralizing activity in $54.2 \%$ in at least 148 one of three assays (Fig. $\mathbf{2} \mathbf{g}, \mathbf{h}$ ). Combining these results and accounting for assay149 specificity (see methods) we show that only $5.6 \%-7.3 \%$ of individuals do not mount a 150 detectable antibody response against SARS-CoV-2. Notably, while only $3.6 \%$ (1 of 28 ) of 151 hospitalized patients and $4.9 \%$ (43 of 877 ) of individuals with mild symptoms lacked anti152 SARS-CoV-2 antibodies, $22.7 \%$ (10 of 44) asymptomatic individuals were negative for a 153 detectable antibody response in at visit 1 . We conclude that $92.7-94.4 \%$ of individuals naturally infected with SARS-CoV-2 mount an antibody response against the virus within the first 12 weeks. Among those, we detected a broad variation in neutralizing activity with approximately $3 \%$ generating a highly potent serum and IgG NAb response.

\section{Sero-reactivity, age, and disease severity predict SARS-CoV-2 neutralization}

159 Next, we analyzed how age, disease severity, gender, and the presence of pre-existing 160 conditions correlate with the anti-spike antibody and SARS-CoV-2 neutralizing response

161 (Fig. 3a, Extended Data Fig. 3). The IgG NAb response was significantly higher in older 162 individuals ( $p<0.0001$ ), with participants $>60$ years comprising $7.7 \%$ of elite- and $42.8 \%$ of 163 high-neutralizers (Fig. 3a). Hospitalized patients and individuals with symptoms had 164 significantly higher NAb activity $(p=0.0008$ and 0.0003 ) compared to asymptomatic 165 individuals, of which $43.2 \%$ (25 of 44) lacked detectable IgG NAbs (Fig. 3a). Males showed 166 higher SARS-CoV-2 neutralization than females (GeoMean IC $50136.3 \mu \mathrm{g} / \mathrm{ml}$ vs. $188.4 \mu \mathrm{g} / \mathrm{ml}$; $167 \mathrm{p}<0.0001)$. In addition, individuals with pre-existing conditions had slightly higher NAb 168 activity compared to those without them (GeoMean $\mathrm{IC}_{50} 161.9 \mu \mathrm{g} / \mathrm{ml}$ vs. $174.6 \mu \mathrm{g} / \mathrm{ml} ; \mathrm{p}=$ 169 0.022; Fig. 3a). Similar to IgG NAb activity, serum neutralizing activity and anti-spike 
170 antibodies were also higher in older individuals, patients with a more severe course of

171 disease, and males (Extended Data Fig. 3a-c). Next, we performed a multivariate statistical

172 analysis to determine the interplay between clinical features and the NAb response. Features

173 included gender, age, disease severity, presence of pre-existing conditions, disease

174 symptoms (Supplementary Table 1), weeks since disease onset, and the anti-spike IgG/lgA

175 ELISA measurements. We applied a stepwise regression that adds new features only if they

176 significantly improved the model according to a likelihood ratio test. The resulting $\mathrm{IC}_{50}$

177 prediction model (Adjusted $\mathrm{R}^{2}=0.461$ ) revealed that IgG antibody levels are most predictive

178 for SARS-CoV-2 neutralizing activity $\left(p=10^{-99}\right)$, followed by age $\left(p=6 \cdot 1^{*} 10^{-7}\right)$, IgA antibody

179 levels $\left(p=7.6^{*} 10^{-6}\right)$, time since disease onset $(p=0.01)$ and fever during infection $(p=0.02$;

180 Fig. 3b, c). Similarly, age, anti-spike antibody levels, times since disease onset and fever during acute infection were also found to be highly predictive of serum $\mathrm{ID}_{50}$ (Extended Data

182 Fig. 4a, 4b). Additionally, we built a Bayesian network model to determine the feature 183 dependencies and how they predict the SARS-CoV-2 IgG neutralizing response (Fig. 3d).

184 When applying the stepwise regression model only for predicting the presence of anti-spike antibodies, we observed that gender $\left(\operatorname{lgG} p=8.5^{*} 10^{-5} ; \lg \mathrm{A} p=2.2^{*} 10^{-10}\right)$ and the disease symptoms, cough $(\lg A p=0.01)$, diarrhea $(\lg G p=0.02)$ or change in taste $(\lg g p=0.002$; $\lg \mathrm{A} p=0.04)$ are predictive of anti-spike antibody levels (Extended Data Fig. 4b, c). In addition, we investigated the possible effect of viral load obtained from naso-/oro-pharyngeal swabs at the time of diagnosis on the antibody response at study visit 1 , but no correlation

190 was found (Extended Data Fig. 4d, e). In summary, higher IgG levels, older age and fever 191 during acute infection are highly predictive of the development of SARS-CoV-2 neutralizing 192 activity. 
197 associated with the development of effective humoral immunity, ii.) to guide vaccine design,

198 and iii.) to isolate highly potent neutralizing monoclonal antibodies ${ }^{39}$. In order to characterize

199 the small fraction of SARS-CoV-2 elite neutralizers in our cohort (3\%; IC $50<20 \mu \mathrm{g} / \mathrm{ml}$; Fig.

200 2b), we selected 15 individuals of each group of non, low, average, high and elite-

201 neutralizers (Extended Data Fig. 5a-c) testing them against authentic SARS-CoV-2 as well

202 as SARS-CoV-1 pseudovirus. Neutralization of SARS-CoV-2 pseudovirus against authentic virus correlated closely in all groups with authentic virus (spearman $r=0.79$; Extended data

Fig. 5d). SARS-CoV-1 neutralization was not observed in non- and low-neutralizers and only in 1 out of 15 average neutralizers. However, in the high and elite neutralizing groups, 8/15 and 15/15 samples carried SARS-CoV-1 cross-neutralizing activity, respectively, with potencies $\left(\mathrm{IC}_{50}\right)$ as low as $5.1 \mu \mathrm{g} / \mathrm{ml} \mathrm{lgG}$. Of note, while all SARS-CoV-2 elite neutralizers demonstrated SARS-CoV-1 cross-neutralization, variation in potency is ranging from 12.1 $634.9 \mu \mathrm{g} / \mathrm{ml}$ and an overall low correlation (spearman $\mathrm{r}=0.3745 ;$ Fig. $4 \mathrm{~b}$ ). Next, we studied the neutralizing potency of the elite neutralizers against six different SARS-CoV-2 strains carrying several mutations that became prominent at a global level ${ }^{40}$ (Fig. 4c, Extended

212 Data Fig. 5). IgG from elite neutralizers was potent against all tested SARS-CoV-2 strains 213 including both S1 and S2 mutants as well as variants (BAVP1, DRC94) carrying the D614G

214 mutation (Fig. 4c, Extended Data Fig. 5). We conclude, that individuals mounting a potent SARS-CoV-2 NAb response possess cross-reactive antibodies against SARS-CoV-1 without any known prior exposure and are effective in neutralizing various prevalent SARS-CoV-2 strains.

In order to study antibody kinetics, we first investigated the development of SARS-CoV-2directed antibodies in the first 4 weeks after disease onset. To this end, we evaluated 259 samples obtained from an additional 110 individuals. In this subgroup, $44.5 \%$ and $54,5 \%$ were male and female, respectively, and $41.8 \%$ had been hospitalized (Extended Data Fig. 
224 6a). Anti-spike IgG and IgA could be detected in some people within the first week after 225 disease onset, with IgA levels starting to decline by week 4 (Extended Data Fig. 6b). Out of 226 the 24 individuals that were closely monitored, most individuals sero-converted between 2-3 227 weeks post disease onset (Extended Data Fig. 6b).

228 In order to assess longevity of humoral immunity following SARS-CoV-2 infection, we applied 229 a linear regression mixed effects model to antibody measurements obtained between 3.1 to 23041.9 weeks post infection. The half-life of anti-spike lgG was estimated to be 34.9 weeks 231 (Fig. 5a). For systematic tracking of the antibody response within individuals, we analyzed anti-spike antibodies in 131 individuals at 4 study visits (range 3.1 to 38.7 weeks post disease onset; Fig. 5b, c). The data show that $\lg$ levels decrease between $1^{\text {st }}$ to $2^{\text {nd }}$ study

234 visit (Geo. Mean $\mathrm{S} / \mathrm{C} 0=4.6$ vs. Geo. Mean $\mathrm{S} / \mathrm{C} 0=3.7$ ) followed by a relatively constant $\lg \mathrm{G}$ 235 levels for 10 months after infection (Geo. Mean $\mathrm{S} / \mathrm{C} 0=3.0$ ) (Fig. 5b, Supplementary Table 236 1). While the detection of S1-reactivity stays equal at first and second visit (86\%), the fraction 237 of individuals that are reactive for S1-reactive antibodies decays to $79 \%$ (7\% drop from visit 238 1) at the third visit and to $73 \%$ (13\% drop from visit 1) at visit 4 (9-10 months post disease 239 onset).

240 NAb activity was longitudinally monitored for 342 individuals from visit 1 (median 6.4 weeks 241 post infection) to visit 2 (median 17.3 weeks post infection) (Fig. 5d-g). Regression modeling showed that serum NAb titers had a short half-life of 6.7 weeks compared to a much longer 243 30.8-week half-life for IgG NAb titers (Fig. 5d, e). Out of 342 individuals, $87.1 \%$ had serum 244 NAb activity at visit 1 whereas only $70.5 \%$ had NAb activity remaining at visit 2 (Fig. $\mathbf{5 f}$ ). The 245 overall fraction of $\operatorname{lgG}$ neutralizers changed from $82 \%$ to $75 \%$ between visit 1 and 2 . The 246 most dramatic drop from Geo Mean $\mathrm{IC}_{50}$ of $16.23 \mu \mathrm{g} / \mathrm{ml}$ to $45.54 \mu \mathrm{g} / \mathrm{ml}$ was detected in elite 247 neutralizers, $88 \%$ of whom lost their 'elite' status. $23.9 \%$ of average/low neutralizers at visit 1 248 became negative at visit 2 (Fig. $\mathbf{5 g}$ ). Approximately $11 \%$ of individuals did not develop any 249 NAbs and remained serum and IgG-negative at both visits. Overall, only $2.4 \%$ of the cohort 
250 lost detectable antibody responses against SARS-CoV-2 between 1.5 and 4.5 months post

251 infection (Extended data figure 7a-e).

252 In summary, these results show that in most individuals anti-spike IgG antibody levels are 253 maintained for 10 months with a half-life estimate of 8.7 months. Moreover, even though 254 there is a rapid decline in serum NAb activity, IgG NAb function remains relatively constant 255 with an estimated half-life of 7.7 months. We conclude that although there is a decay of 256 antibody titers in serum, the humoral IgG response persists for as long as 10 months after 257 SARS-CoV-2 infection.

\section{Discussion}

260 In order to end the COVID-19 pandemic, widespread SARS-CoV-2 protective immunity will 261 be required. Antibodies are critical for effective clearance of pathogens and for prevention of 262 viral infections ${ }^{41}$. In this study, we examined the neutralizing antibody response in 963 263 individuals who had recently recovered from SARS-CoV-2 infection. The cohort consists primarily $(91.69 \%)$ of patients with mild COVID-19 therefore representing the predominant clinical course of this disease ${ }^{6}$. Since higher disease severity was shown to correlate with higher antibody responses ${ }^{14,42}$, cohorts mainly composed of hospitalized individuals have

267 limited applicability on the majority of COVID-19 cases $^{20,35,43,44}$. Moreover, to our knowledge 268 this is the most comprehensive study $(n=963)$, in which neutralizing antibody activity has 269 been reported to date with the next largest study having analyzed 4-5 fold less individuals at 270 a single time point ${ }^{45}$.

271 Upon recovery from COVID-19, we detected the development of a broad spectrum of IgG 272 neutralizing activity ranging from no neutralization (threshold $\mathrm{IC}_{50}<750 \mu \mathrm{g} / \mathrm{ml}, 21 \%$ ) to low $273\left(\mathrm{IC}_{50}=50-750 \mu \mathrm{g} / \mathrm{ml}, 10 \%\right)$, average $\left(\mathrm{IC}_{50}=100-500 \mu \mathrm{g} / \mathrm{ml}, 44.8 \%\right)$, high $\left(\mathrm{IC}_{50}=20-100\right.$ $274 \mu \mathrm{g} / \mathrm{ml}, 20.9 \%$ ), and elite SARS-CoV-2 neutralization $\left(\mathrm{IC}_{50}<20 \mu \mathrm{g} / \mathrm{ml}, 3.3 \%\right) .94 .4 \%$ of 275 individuals were found to possess S- or N-reactive antibodies or neutralizing activity at serum 
276 or IgG level. Thus, while most individuals develop a detectable antibody response upon 277 natural infection, the extent of SARS-CoV-2 neutralizing activity is highly variable with the 278 fraction of non-responders being highest for asymptomatic individuals (23\%).

279 The broad spectrum of neutralizing activity developed in COVID-19 recovered individuals 280 may impact the level of protective immunity. For instance, asymptomatic infection is 281 estimated to account for up to $40 \%$ of all infections ${ }^{46}$. In these individuals and in other 282 patients with weak antibody responses, lower IgG titers may contribute to a higher 283 susceptibility to re-infection. Recently, mutated virus strains were reported ${ }^{47,48}$, some of which possess mutations causing partial resistance to convalescent plasma ${ }^{48}$ or SARS-CoV-

2852 monoclonal antibodies ${ }^{49}$. A weak antibody response may help propagate escape variants 286 and may therefore complicate effective measures to combat the COVID-19 pandemic.

287 To guide vaccine strategies based on population demographics, it is critical to understand which clinical features affect the development of antibody responses. NAb response presented here is comparable to recent spike-based mRNA vaccine studies in age group 18-

29055 , where geometric mean neutralizing titers were in the range of $100-300 I D_{50}$ (depending 291 on dose) 1.5 months post vaccination ${ }^{17,50}$ versus 111.3 ID $_{50}$ in this study. Recent studies 292 have reported that age, gender and disease severity ${ }^{14,36,44}$ can impact SARS-CoV-2 NAb 293 titers $^{14,36,42,43,45}$. However, a comprehensive analysis on a large representative cohort was 294 missing. Using multivariate statistical analysis on the antibody measurements and clinical 295 data, we found that higher anti-spike antibody levels, older age, symptomatic infection and a 296 severe course of COVID-19 were highly predictive of NAb titers. Notably, based on previous 297 vaccine studies $^{51}$, it was frequently speculated that older individuals might generate a less 298 efficient immune responses to SARS-CoV-2 infection or vaccination. However, based on our 299 data, the $>60$ age group had the highest level of neutralizing $\operatorname{lgG}$ antibodies (mean $\mathrm{IC}_{50}=$ $30084.8 \mu \mathrm{g} / \mathrm{ml}$, mean $\mathrm{ID}_{50}$ serum titer $\left.=276.6\right)$.

301 In some individuals we detected very high levels of SARS-CoV-2 neutralizing activity $\left(\mathrm{IC}_{50}<\right.$ $30220 \mu \mathrm{g} / \mathrm{ml}, \mathrm{ID}_{50}$ serum titer $>2,500$ ) ranking them as 'elite neutralizers'. While cross-reactivity 
against SARS-CoV-1 and other Beta-CoVs has been shown for some SARS-CoV-2

304 recovered individuals ${ }^{52-54}$, we revealed that all elite neutralizers have cross-reactive $\lg$ NAbs against SARS-CoV-1. Moreover, IgG from elite neutralizers could efficiently block infection of 6 SARS-CoV-2 strains. Two of them (BavP1 and DRC94) contain the D614G mutation in the S protein ${ }^{55}$ associated with higher infectivity ${ }^{56}$. Given the eminent risk of novel emerging CoVs and monoclonal antibody-resistant SARS-CoV-2 variants, developing antibodies with broader neutralization breadth would be critical. Further evaluation of the antibody response in such elite neutralizers at the single B cell level will be required to understand the details of such potent NAb responses and can yield the identification of new

312 highly potent cross-reactive monoclonal antibodies.

313 Effective neutralization and clearance of pathogens is mainly mediated by $\lg$ antibodies,

314 which are typically formed within 1-3 weeks post infection and often provide long-term 315 immunity that can last decades ${ }^{57}$. Protective immunity to seasonal coronaviruses like NL63, $316229 \mathrm{E}, \mathrm{OC} 43$ and HKU1 is known to be short lived and re-infection is common ${ }^{58}$. In addition, 317 the antibody response to SARS-CoV-1 and Middle East Respiratory Syndrome (MERS)-CoV 318 was shown to wane over time ${ }^{59}$. Upon SARS-CoV-1 infection, serum IgG and NAbs were 319 shown to decline 3 years after infection ${ }^{60}$. This suggests that immunity to CoVs is rather short 320 lived compared to some other viruses such as measles virus, for which life-long antibody 321 immunity is observed ${ }^{57}$. In our study we not only measured serum neutralization, but also 322 quantified SARS-CoV-2 IgG neutralizing activity. While serum neutralization waned quickly 323 (half-life of 1.5 months), levels of purified $\operatorname{lgG}$ rather persisted with a longer half-life of 7.7 months. The sharp drop in serum neutralization could be a consequence of a decline in antispike $\lg \mathrm{A}$ and $\lg \mathrm{M}$ titers $^{34}$, which along with $\lg$, cumulatively contribute to serum NAb 326 activity ${ }^{61}$. Finally, SARS-CoV-2 spike-based mRNA vaccines ${ }^{17}$ were shown to induce NAb 327 titers in different age groups for a time span up to 4.25 months $^{18}$. In this study, we found that 328 although SARS-CoV-2-reactive IgG levels decline by $17 \%$ within the first 4 months after 329 infection, anti-spike $\operatorname{lgG}$ can be persistently detected in the majority of COVID-19 cases for 330 up to 10 months post infection. 
331 In summary, the data presented in this study provides new insight into the features that

332 shape the SARS-CoV-2 NAb response in COVID-19 recovered individuals. Longitudinal

333 mapping of antibody responses reveals a relatively long-lived IgG antibody response lasting

334 up to 10 months. Since many SARS-CoV-2 vaccines are spike protein-based ${ }^{62}$, studying 335 antibody dynamics informs us on longevity of natural immunity as well as may help to inform 336 on vaccination strategies and outcomes in the population.

\section{Methods}

\section{Enrollment of participants and study design}

340 Blood samples were collected from donors who gave their written consent under the

341 protocols 20-1187 and 16-054, approved by the Institutional Review Board (IRB) of the

342 University Hospital Cologne. All samples were handled according to the safety guidelines of

343 the University Hospital Cologne. Individuals that met the inclusion criteria of i.) $\geq 18$ years old

344 and ii.) history of SARS-CoV-2 positive polymerase chain reaction (PCR) from nasopharyngeal swab or collected sputum, and/or iii.) an onset of COVID-19 specific

346 symptoms longer than 3 weeks ago, were enrolled in this study. Demographical data,

347 COVID-19-related pre-existing conditions, and information on the clinical course were 348 collected at study visit 1 . Blood samples were collected starting from study visit 1 , for up to 4 349 follow up visits between the $6^{\text {th }}$ of April and $17^{\text {th }}$ of December 2020.

\section{Processing of serum, plasma and whole blood samples}

351 Blood samples were collected in Heparin syringes or EDTA monovette tubes (Becton

352 Dickinson) and fractionated into plasma and peripheral blood mononuclear cell (PBMC) by

353 density gradient centrifugation using Histopaque-1077 (Sigma). Plasma aliquots were stored

354 at $-80^{\circ} \mathrm{C}$ till use. Serum was collected from Serum-gel tubes (Sarstedt) by centrifugation and 355 stored at $-80^{\circ} \mathrm{C}$ till use. 


\section{Isolation of IgGs from serum and plasma samples}

357 For the isolation of total $\mathrm{lgG}, 0.5-1 \mathrm{~mL}$ plasma or serum was heat inactivated at $56^{\circ} \mathrm{C}$ for 45 358 minutes and incubated overnight with Protein G Sepharose 4 Fast Flow beads (GE

359 Healthcare) at $4^{\circ} \mathrm{C}$. Next day, beads were washed on chromatography columns (BioRad)

360 and Protein $\mathrm{G}$ bound $\mathrm{IgG}$ was eluted using $0.1 \mathrm{M}$ Glycine $\mathrm{pH}=3$ and instantly buffered in $1 \mathrm{M}$

361 Tris $\mathrm{pH}=8$. Buffer exchange to PBS (Gibco) was performed using $30 \mathrm{kDa}$ Amicon Ultra-15

362 columns (Millipore) and the purified IgG was stored at $4^{\circ} \mathrm{C}$.

\section{Cloning of SARS-CoV-2 spike variants}

364 The codon optimized SARS-CoV-2 Wu01 spike (EPI_ISL_40671) was cloned into 365 pCDNA ${ }^{\mathrm{TM}}$ 3.1/N5-HisTOPO vector (Invitrogen). SARS-2-S global strains (BavP1

366 EPI_ISL_406862; $\quad$ ARA36 EPI_ISL_418432; DRC94 EPI_ISL_417947; $\quad$ CA5

367 EPI_ISL_408010; NRW8 EPI_ISL_414508) were generated by introducing the 368 corresponding amino acid mutations (Extended Data Fig. 5) using the Q5® Site-Directed 369 Mutagenesis Kit (NEB) and per manufacturer's protocol.

370 Production of SARS-CoV pseudovirus particles

371 Pseudovirus particles were generated by co-transfection of individual plasmids encoding

372 HIV-1 Tat, HIV-1 Gag/Pol, HIV-1 Rev, luciferase followed by an IRES and ZsGreen, and the 373 SARS-CoV-2 spike protein as previously described ${ }^{63}$. In brief, HEK 293T cells were

374 transfected with the pseudovirus encoding plasmids using FuGENE 6 Transfection Reagent

375 (Promega). The virus culture supernatant was harvested at $48 \mathrm{~h}$ and $72 \mathrm{~h}$ post transfection 376 and stored at $-80^{\circ} \mathrm{C}$ until use. Each virus batch was titrated by infecting 293T-ACE2 and after 377 a 48 -hour incubation period at $37^{\circ} \mathrm{C}$ and $5 \% \mathrm{CO}_{2}$, luciferase activity was determined after 378 addition of luciferin/lysis buffer (10 mM MgCl2, $0.3 \mathrm{mM}$ ATP, $0.5 \mathrm{mM}$ Coenzyme A, $17 \mathrm{mM}$

379 IGEPAL (all Sigma-Aldrich), and $1 \mathrm{mM}$ D-Luciferin (GoldBio) in Tris-HCL) using a microplate 380 reader (Berthold). An RLU of approximately 1000-fold in infected cells versus non-infected 381 cells was used for neutralization assays. 
For testing SARS-CoV-2 neutralizing activity of IgG or serum/plasma samples, serial dilutions of $\operatorname{lgG}$ or serum/plasma (heat inactivated at $56^{\circ} \mathrm{C}$ for $45 \mathrm{~min}$ ) were co-incubated with pseudovirus supernatants for $1 \mathrm{~h}$ at $37^{\circ} \mathrm{C}$ prior to addition of $293 \mathrm{~T}$ cells engineered to express ACE2 ${ }^{63}$. Following a 48 -hour incubation at $37^{\circ} \mathrm{C}$ and $5 \% \mathrm{CO}_{2}$, luciferase activity was determined using the reagents described above. After subtracting background relative luminescence units (RLUs) of non-infected cells, $50 \%$ inhibitory concentrations (IC50s) were determined as the $\lg$ concentrations resulting in a $50 \%$ RLU reduction compared to untreated virus control wells. $50 \%$ Inhibitory dose $\left(\mathrm{ID}_{50}\right)$ was determined as the serum dilution resulting in a $50 \%$ reduction in RLU compared to the untreated virus control wells.

392 Each IgG and serum sample were measured in two independent experiments on different 393 days and the average $I C_{50}$ or $I_{50}$ values have been reported. For each run, a SARS-CoV-2

394 neutralizing monoclonal antibody was used as control to ensure consistent reproducibility in experiments carried out on different days. Assay specificity calculated using pre-COVID-19 samples was found to be $100 \% . \quad I C_{50}$ and $I D_{50}$ values were calculated in GraphPad Prism 7.0 by plotting a dose response curve.

\section{SARS-CoV-2 live virus isolation from nasopharyngeal swabs}

399 For outgrowth cultures of authentic SARS-CoV-2 from nasopharyngeal swabs, $1 \times 10^{6}$ VeroE6

400 cells were seeded onto a T25 flask (Sarstedt) on the previous day DMEM (Gibco) containing $40110 \%$ FBS, 1\% PS, $1 \mathrm{mM}$ L-Glutamine and $1 \mathrm{mM}$ Sodium pyruvate. $0.2 \mathrm{~mL}$ swab in VNT 402 medium was diluted with $0.8 \mathrm{~mL}$ DMEM (Gibco) containing $2 \% \mathrm{FBS}, 1 \% \mathrm{PS}, 1 \mathrm{mM} \mathrm{L}-$

403 Glutamine and $1 \mathrm{mM}$ Sodium pyruvate. The swab dilution was added to VeroE6 cells and left 404 for 1 hour at $37^{\circ} \mathrm{C}, 5 \% \mathrm{CO}_{2}$ after which an additional $3 \mathrm{~mL}$ medium was added. The cultures 405 were examined for the next days for CPE and samples were sent for viral load analysis to 406 track growth of virus by E-gene qPCR. Cell culture supernatant was harvested from positive 407 cultures and stored at $-150^{\circ} \mathrm{C}$ until use. Virus was titrated by adding serial dilutions of virus 408 supernatant (8 replicates) on VeroE6 cells in DMEM (Gibco) containing $2 \%$ FBS, $1 \%$ PS, 
$4091 \mathrm{mM}$ L-Glutamine and $1 \mathrm{mM}$ Sodium pyruvate. After 4 days of incubation at $37^{\circ} \mathrm{C}, 5 \% \mathrm{CO}_{2}$,

410 the presence or absence of cytopathic effects (CPE) was noted in using a brightfield

411 microscope. TCID 50 was calculated using the Spearman and Kaerber algorithm ${ }^{64,65}$.

\section{SARS-CoV-2 live virus neutralization assay}

413 Live SARS-CoV-2 (termed CoV2-P3) was grown out from a swab from Cologne using

414 VeroE6 cells as described above and then expanded in culture by superinfection of VeroE6

415 from the initial outgrowth culture. Whole genome sequencing of the isolated virus was done

416 isolating viral RNA using the QIAamp MinElute Virus Spine kit (Qiagen) and performing

417 Illumina sequencing. The virus spike amino acid sequence (Extended Data Fig. 5) is similar

418 to the Wu01 spike (EPI_ISL_40671) with the exception that it contains the D641G mutation.

419 For the neutralization assay, dilutions of IgG were co-incubated with the virus (1000-2000

$420 \mathrm{TCID}_{50}$ ) for $1 \mathrm{~h}$ at $37^{\circ} \mathrm{C}$ prior to addition of VeroE6 cells in DMEM (Gibco) containing $2 \%$

421 FBS, 1\% PS, 1mM L-Glutamine and 1mM Sodium pyruvate. After 4 days of incubation at $37^{\circ} \mathrm{C}, 5 \% \mathrm{CO}_{2}$, neutralization was analyzed by observing cytopathic effects (CPE) using a brightfield microscope and the highest dilution well with no CPE was noted to be the $\mathrm{IC}_{100}$ for

424 the antibody. Assay specificity calculated using pre-COVID-19 samples was found to be $100 \%$. All samples were measured in two independent experiments on separate days and the average $\mathrm{IC}_{100}$ from all measurements has been reported.

\section{Detection of anti-SARS-CoV-2 spike IgG and IgA by ELISA}

428 For assessing $\lg \mathrm{A}$ and $\lg$ antibody titers, the Euroimmun anti-SARS-CoV-2 ELISA using 429 the S1 domain of the spike protein as antigen was used (Euroimmun Diagnostik, Lübeck,

430 Germany). Serum or plasma samples were tested on the automated system Euroimmun 431 Analyzer I according to manufacturer's recommendations. Signal-to-cut-off (S/CO) ratio was 432 calculated as extinction value of patient sample/extinction value of calibrator. $\lg A$ and $\lg G$ $433 \mathrm{~S} / \mathrm{CO}$ values were interpreted as positive $\mathrm{S} / \mathrm{CO} \geq 1.1$, equivocal $\mathrm{S} / \mathrm{CO} \geq 0.8-<1.1$, and negative $\mathrm{S} / \mathrm{CO}<0.8$. Additional commercial kits used for antibody measurements were also

435 used as per manufacturer's recommendations; Anti-S1/S2 lgG was measured using 
436 DiaSorin's LIAISON® SARS-CoV-2 ELISA kit with the following cut-off values: negative

$437<12.0 \mathrm{AU} / \mathrm{ml}$, equivocal $\geq 12.0-<15.0 \mathrm{AU} / \mathrm{ml}$ and positive $\geq 15.0 \mathrm{AU} / \mathrm{ml}$. Anti-N Pan-lgs were 438 measured using Roche's Elecsys ${ }^{\circledR}-$ Assay with cut-off values: non-reactive $<1,0$ COI and 439 reactive $\geq 1,0 \mathrm{COI}$. Anti-N IgG were measured with Abbott's Alinity i system with cut-off 440 values: positive $\mathrm{S} / \mathrm{CO} \geq 1.4$ and negative $\mathrm{S} / \mathrm{CO}<1.4$. Assay specificities calculated using pre441 COVID-19 samples: Euroimmun IgG 100\%; Euroimmun IgA 96\%; Roche 98\%; Diasorin $44298 \%$; Abbott 98\%.

\section{Measurement of SARS-CoV-2 RNA levels from nasopharyngeal swabs}

444 Cycle threshold values for quantifying viral load in naso/oro-pharyngeal swabs was done by qPCR using LightMix ${ }^{\circledR}$ SarbecoV E-gene ${ }^{66}$ plus EAV control (TIB Molbiol, Berlin, Germany) in combination with the $\mathrm{N}$-gene (inhouse primer sets in multiplex PCR) on LightCycler® 480

447 (Roche Diagnostics).

\section{Statistical modeling}

449 To select features that are predictive for the $\log _{10}$ response in a multivariate analysis (Fig.

$4503 \mathrm{~b})$, forward stepwise regression was applied, using the $p$-value from a likelihood ratio test $(R$ 451 function Imtest::Irtest) as selection criterion in each step. The final multiple linear regression 452 model (Fig. 3c) includes only features that show a significant model improvement 453 (alpha $=0.05)$ in the feature selection phase. To study the interplay of the different features 454 regarding their relationship with the response (Fig. 3d), a Bayesian network was learned by 455 maximizing the BIC score for hybrid networks via hill-climbing (R function bnlearn::hc) ${ }^{67}$. To 456 enforce it to be a sink in the network, all outgoing edges from the response variable were 457 blacklisted prior to learning. For the longitudinal analyses (Fig. 5e-h), linear mixed effect 458 models (R-function nIme:Ime) were applied to all data points from both visits, where each 459 patient has its own intercept. Since a binary transformation of the response was used, half460 life estimates were computed as negative inverse of the common slope regression 461 coefficient. Prediction intervals were computed using R-function ggeffects::.ggpredict ${ }^{68}$. 


\section{Figure legends}

Figure 1: SARS-CoV-2 recovered cohort and study design

464 a, Illustration depicting study timeline and number of individuals analyzed at each study visit.

465 Graph represents sample collection time for participants in weeks since disease onset 466 (symptom onset date or positive PCR date). b, age distribution of the cohort c, gender 467 distribution, presence of pre-conditions and disease severity.

a, pie chart illustrating fraction of serum neutralizers against Wu01 pseudovirus at study visit 1. Violin plot depicts serum $I D_{50}$ values for the neutralizers $(n=793)$, categorized based on serum ID $\mathrm{ID}_{50}$ titers. Dotted line represents the LOD (10-fold dilution) of the assay. $\mathbf{b}$, pie chart depicting the fraction of IgG neutralization against Wu01 pseudovirus at study visit 1 . Violin plot depicts $\operatorname{IgG} I \mathrm{I}_{50}$ values for the neutralizers $(n=760)$, categorized based on $\lg \mathrm{IC}_{50}$. Dotted line represents the LOD $(750 \mu \mathrm{g} / \mathrm{ml})$ of the assay. c, pie chart comparing fraction of samples with neutralization at serum and/or lgG level. Spearman correlation plot between serum $I D_{50}$ and $\lg I C_{50}$ values at study visit 1. d, violin plot of Euroimmun ELISA signal over cut-off $(\mathrm{S} / \mathrm{CO})$ ratios for anti-spike $\mathrm{IgG}$. Dotted line represents $\mathrm{LOD}(\mathrm{S} / \mathrm{CO}=1.1)$ of the assay. e, pie charts illustrating fraction of anti-spike lgG reactive individuals in the Euroimmun ELISA. f, spearman correlation between Euroimmun $\lg \mathrm{S} / \mathrm{CO}$ and $\lg \mathrm{IC}_{50}$ at study visit 1. g, plot depicting binding against spike, Nucleocapsid $(\mathrm{N})$ and neutralizing response against authentic virus (AV) and Wu01 pseudovirus (PSV) of the IgG negative fraction $(n=166)$ with each row representing 1 individual. $\mathbf{h}$, pie charts showing total fraction of individuals with binding or neutralizing activity in the IgG-fraction from g. i, pie chart representing total combined binding and NAb response in the cohort $(n=963)$ and bar graph of the Ab-negative individuals based on disease severity. LOD, limit of detection 
a, violin plots depicting $\lg$ neutralization $I_{50}$ values at study visit 1 against Wu01 pseudovirus, subdivided based on age, disease severity, gender and pre-conditions. Dotted line represents the limit of detection $(750 \mu \mathrm{g} / \mathrm{ml})$ of the assay. Statistical analysis was performed Kruskal-Wallis and Mann-Whitney tests. b, multiple linear regression model for predicting $\lg \mathrm{IC}_{50}$ using the features: Euroimmun $\mathrm{S} / \mathrm{CO}$, gender, age, disease severity, pre-

494 conditions, weeks since infection and the 9 reported symptoms. Plot below depicts model coefficients to study the goodness of fit of the final $\mathrm{IC}_{50}$ prediction model. c, Bayesian network of the features predicting $\lg \mathrm{IC}_{50}$ are plotted using the bnlearn $\mathrm{R}$ package. The graph connects the features which are predictive of each other with $\lg \mathrm{IC}_{50}$ as sink.

Figure 4: Cross-neutralization by SARS-CoV-2 elite neutralizers

a, heat maps visualizing the neutralizing activity of 15 individuals from each neutralization category: Elite-, High-, Average-, Low-, and Non-neutralizers (total n=75) against SARS-

502 CoV-2-S pseudovirus, SARS-CoV-2 authentic virus and SARS-CoV (SARS-1) pseudovirus.

503 b, Spearman correlation of IgG IC $I_{50}$ against SARS-2-S and SARS-1-S pseudovirus. c, details on the

504 source and type of spike mutations in 6 global strains of SARS-CoV-2 generated and used in 505 this study. $\mathbf{d}$, heat map visualizing the $I_{50}$ values of 15 Elite-neutralizers against the 6 SARS-CoV-2 global spike variants from c. anti-spike IgG levels using a linear mixed-effects model. b, longitudinal mapping of IgG levels

511 in 131 individuals from visit 1-4. Dot plots illustrate antibody titer against the weeks since 512 infection to study visit 1 (red) and study visit 2 (blue). Geometric mean change shown in 
513 black. Dotted lines represent limit of detection $(S / C O=1.1$ for IgG ELISA). c, pie charts

514 illustrate the change in the fraction of IgG ELISA positive (Pos), Negative (Neg) and

515 Equivocal (Equi) samples $(n=131)$ between the study visits. $d$, serum $I_{50}$ values against

516 Wu01 pseudovirus $(n=1,017)$ and $e, \lg I C_{50}$ values against Wu01 pseudovirus $(n=996)$

517 plotted against weeks since infection for half-life estimate of the antibody levels using a linear

518 mixed effects model. Longitudinal mapping of serum neutralization (f) and $\lg$ Geutralization

519 (g) in 342 individuals at study visit 1 and 2. Serum and IgG non-neutralizers were assigned

520 values of $I D_{50}=5$ and $I C_{50}=900$ for plotting. Dotted lines represent limit of detection $\left(I D_{50}\right.$ of 10

521 and $\mathrm{IC}_{50}$ of $750 \mu \mathrm{g} / \mathrm{ml}$ for serum and $\mathrm{IgG}$ neutralization assays). Pie charts illustrate the

522 change in the fraction of serum neutralizers (f) and $\operatorname{lgG}$ neutralizers $(\mathbf{g})$ in the samples $523(n=342)$ between the study visits.

a, Illustration depicting processing of blood samples and IgG purification from plasma or serum samples. b, Plot analyzing the efficiency of IgG purification from plasma or serum as compared to clinical reference range. Statistical testing performed with Kruskal-Wallis test. Validation of the pseudovirus neutralization test against SARS-2-S Wu01 pseudovirus using Pre-COVID-19 plasma (c) and IgG (d) samples with a neutralizing monoclonal antibody as positive control ${ }^{28}$.

\section{Extended Data Figure 2: Correlation between neutralization and serology results}

534 a, violin plot of Euroimmun ELISA signal over cut-off (S/CO) ratios for anti-spike IgA. Dotted

535 line represents the limit of detection $(S / C O=1.1)$ of the assay. $\mathbf{b}$, Spearman correlation plot

536 between Euroimmun $\operatorname{IgA} S / C O$ and serum $I_{50}$ values at study visit 1 . Euroimmun IgA S/CO

537 and serum $I D_{50}$ values at study visit 1 . Pie charts illustrating the fraction of serum neutralizers

538 and non-neutralizers and their corresponding Euroimmun IgA ELISA result for comparison. c, 
539 Spearman correlation plot of Euroimmun IgG S/CO ratios vs. IgA S/CO ratios at study visit 1.

540 d, Spearman correlation plot between Euroimmun $\lg \mathrm{S} / \mathrm{CO}$ and serum $\mathrm{ID}_{5} 0$ values at study

541 visit 1. Pie charts illustrating the fraction of serum neutralizers and non-neutralizers and their 542 corresponding Euroimmun IgG ELISA result for comparison.

544 Extended Data Figure 3: Correlates of anti-SARS-CoV-2 antibody titers

545 a, violin plots depicting serum neutralization at study visit 1 against Wu01 pseudovirus, 546 subdivided based on age, disease severity, gender and pre-conditions. Dotted line 547 represents the limit of detection (1:10 dilution) of the assay. $\mathbf{b}$, violin plots depicting

548 Euroimmun IgG ELISA S/CO at study visit 1, subdivided based on age, disease severity, 549 gender and pre-conditions. Dotted line represents the limit of detection $(\mathrm{S} / \mathrm{CO}=1.1)$ of the 550 assay. c, violin plots depicting Euroimmun IgA ELISA S/CO at study visit 1, subdivided based 551 on age, disease severity, gender and pre-conditions. Dotted line represents the limit of 552 detection $(\mathrm{S} / \mathrm{CO}=1.1)$ of the assay. $\mathbf{a}, \mathbf{b}$ and $\mathbf{c}$ Statistical analysis was performed using Kruskal-Wallis and Mann-Whitney tests.

a, multiple linear regression model and model coefficients for predicting serum neutralization using the features: Euroimmun S/CO, gender, age, disease severity, pre-conditions, weeks since infection and the 9 reported symptoms. $\mathbf{b}$, Bayesian network of the features predicting serum $I_{50}$ are plotted using the bnlearn $\mathrm{R}$ package. The graph connects the features which

560 are predictive of each other with serum $\mathrm{ID}_{50}$ as sink. $\mathbf{c}$ and $\mathbf{d}$, Multiple linear regression

561 model for predicting $\lg G$ and $\lg A$ ratios using the features: gender, age, disease severity,

562 pre-conditions, weeks since infection and the 9 reported symptoms. Plots on the right depicts model coefficients to study the goodness of fit of the corresponding final models. Spearman 
564 correlation plot for diagnostic naso-/oro-pharyngeal swab Ct values for E-gene (e) or N-gene

565 (f) vs. IgG $I C_{50}$, serum $I D_{50}$, anti-spike $\lg G$ and anti-spike $\lg A$ values at study visit 1.

567 Extended Data Figure 5: Neutralization of different strains by SARS-CoV-2 eliteneutralizers

a, plots for the distribution of gender, age and time since infection for the 15 individuals selected randomly from the five IgG neutralization categories: elite-, high-, average-, low-, and non-neutralizers ( $\mathrm{n}=75$ total). Statistical testing performed with Kruskal-Wallis test using Dunn's multiple comparisons. b, Spearman correlation of IgG IC50 against SARS-2-S pseudovirus and SARS-2 authentic virus. c, Relative infectivity of SARS-CoV-2 global strain

574 pseudovirus in 293T-ACE2 cells. d, Sequence alignment of the spike amino acid sequence 575 of the 6 global SARS-CoV-2 strains and SARS-1 used for pseudovirus neutralization assays 576 in this study.

a, Pie charts indicating distribution of gender and disease severity in individuals who were longitudinally monitored starting from the early phase of infection. b, Plots depicting $\lg G$ and $\lg \mathrm{A}$ ratios over time in individuals $(n=107)$. Dotted line represents the limit of detection

$582(\mathrm{~S} / \mathrm{CO}=1.1)$ of the Euroimmun ELISA. Statistical analysis was performed using a second order polynomial quadratic equation $\left(R^{2}=0.128\right.$ for $\lg G$ and $R^{2}=0.140$ for $\left.\lg A\right)$ with $95 \%$ confidence interval shading ( $\lg G$ in blue and $\lg \mathrm{A}$ in red) of the best line. c, Individual plots depicting $\lg G$ (blue) and $\lg A$ (red) levels over time. Gender and disease severity are indicated within each plot. Dotted line represents the limit of detection $(S / C O=1.1)$ of the

587 Euroimmun ELISA. 
a, plot depicting SARS-CoV-2 S1 binding and Wu01 pseudovirus neutralization of 339 individuals at visit 1 and visit 2 with each row representing 1 individual. Bar graphs showing change in fraction of individuals negative for anti-spike Abs (b), anti-spike NAbs (c) or any Ab response (d). e, pie chart evaluating the total presence if $A b$ response between visit 1 and 2 for all individuals.

All data including virus spike sequences are available in the manuscript main figures or supplementary material.

\section{Acknowledgements}

602 We are extremely grateful to all study participants who took part in this study; members of 603 the Klein lab for helpful discussions; Reinhild Brinker, Marie Wunsch and Maike Wirtz for 604 technical support; Daniela Weiland and Nadine Henn for project and laboratory management 605 support; Stefan Poehlmann and Markus Hoffmann for sharing the Wuhan SARS-2-S spike 606 construct; Jesse Bloom and Kate Crawford for sharing 293T-ACE2 cells and lentiviral 607 constructs for production of SARS-CoV pseudovirus particles; Jason McLellan and 608 Nianshuang Wang for sharing the SARS-1-S spike construct; Stephan Becker and Verena 609 Kraehliv for sharing VeroE6 cells; Jeorg Timm, Andreas Walker and Max Damagnez for 610 SARS-CoV-2 virus genome sequencing. This work was funded by grants to Florian Klein

611 from the German Center for Infection Research (DZIF), the German Research Foundation 612 (DFG) CRC1279 and CRC1310, European Research Council (ERC) ERC-stG639961 and 613 COVIM: „NaFoUniMedCovid19“ (FKZ: 01KX2021). 


\section{Author contributions}

616 F.Klein and K.V. conceptualized and designed the study; F.Klein, C.L., G.F. and N.P. 617 provided supervision; K.V. and F.Klein wrote the first draft of the manuscript, all authors 618 reviewed the manuscript draft and agree to the final version; M.A., P.S., L.G., F.D., V.C., 619 H.G., C.H., I.S., N.J., were involved in study participant interaction including obtaining 620 informed consent, clinical data and sample collection and writing the study protocol. K.V. and 621 F.Kleipass performed neutralization assays; V.C. and W.J. obtained ELISA data; F.Kleipass 622 and K.V. performed IgG purification; K.V., V.C., F.K., F.D., P.S. analyzed data; K.V. 623 performed final data analysis and R.E. performed statistical analysis; M.S., M.S.E., R.S. and P.M. processed blood samples; K.E., S.S. and E.H. were involved in data collection.

\section{References}

6271 Zhu, N. et al. A Novel Coronavirus from Patients with Pneumonia in China, 2019. $N$ $628 \quad$ Engl J Med 382, 727-733, doi:10.1056/NEJMoa2001017 (2020).

6292 Zhou, P. et al. A pneumonia outbreak associated with a new coronavirus of probable bat origin. Nature 579, 270-273, doi:10.1038/s41586-020-2012-7 (2020). Huang, C. et al. Clinical features of patients infected with 2019 novel coronavirus in Wuhan, China. The Lancet 395, 497-506, doi:10.1016/s0140-6736(20)30183-5 (2020). Mizrahi, B. et al. Longitudinal symptom dynamics of COVID-19 infection. Nat Commun 11, 6208, doi:10.1038/s41467-020-20053-y (2020).

636

637

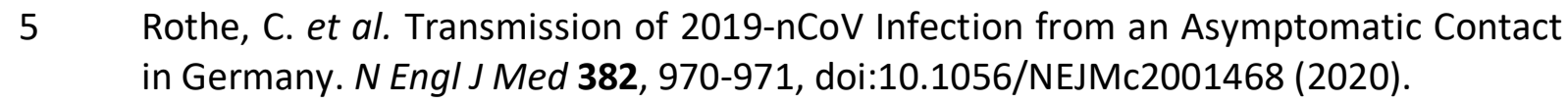
Williamson, E. J. et al. Factors associated with COVID-19-related death using OpenSAFELY. Nature 584, 430-436, doi:10.1038/s41586-020-2521-4 (2020).

640

641 7 Wolfel, R. et al. Virological assessment of hospitalized patients with COVID-2019. Nature 581, 465-469, doi:10.1038/s41586-020-2196-x (2020).

$8 \mathrm{He}, \mathrm{X}$. et al. Temporal dynamics in viral shedding and transmissibility of COVID-19. Nat Med 26, 672-675, doi:10.1038/s41591-020-0869-5 (2020).

9 Galvan-Tejada, C. E. et al. Persistence of COVID-19 Symptoms after Recovery in Mexican Population. Int J Environ Res Public Health 17, doi:10.3390/ijerph17249367 (2020).

64610 Cirulli, E. T. et al. Long-term COVID-19 symptoms in a large unselected population. doi:10.1101/2020.10.07.20208702 (2020).

11 Huang. 6-month consequences of COVID-19 in patients discharged from hospital: a cohort study. Lancet, doi:https://doi.org/10.1016/S0140-6736(20)32656-8 (2021). Glycoprotein. Cell 181, 281-292 e286, doi:10.1016/j.cell.2020.02.058 (2020). 
13 Hoffmann, M. et al. SARS-CoV-2 Cell Entry Depends on ACE2 and TMPRSS2 and Is Blocked by a Clinically Proven Protease Inhibitor. Cell, doi:10.1016/j.cell.2020.02.052 (2020).

14 Piccoli, L. et al. Mapping Neutralizing and Immunodominant Sites on the SARS-CoV-2 Spike Receptor-Binding Domain by Structure-Guided High-Resolution Serology. Cell, doi:10.1016/j.cell.2020.09.037 (2020).

659

15 Rydyznski Moderbacher, C. et al. Antigen-Specific Adaptive Immunity to SARS-CoV-2

660 in Acute COVID-19 and Associations with Age and Disease Severity. Cell 183, 9961012 e1019, doi:10.1016/j.cell.2020.09.038 (2020).

661

$16 \mathrm{Ni}$, L. et al. Detection of SARS-CoV-2-Specific Humoral and Cellular Immunity in

662

663

664 COVID-19 Convalescent Individuals. Immunity

52, 971-977 e973, doi:10.1016/j.immuni.2020.04.023 (2020).

665

666

17 Sahin, U. et al. COVID-19 vaccine BNT162b1 elicits human antibody and TH1 T cell responses. Nature 586, 594-599, doi:10.1038/s41586-020-2814-7 (2020).

18 Widge, A. T. et al. Durability of Responses after SARS-CoV-2 mRNA-1273 Vaccination.

667

668 N Engl J Med, doi:10.1056/NEJMc2032195 (2020).

19 Long, Q. X. et al. Antibody responses to SARS-CoV-2 in patients with COVID-19. Nat

669 Med 26, 845-848, doi:10.1038/s41591-020-0897-1 (2020).

671

672

673 20 Seow, J. et al. Longitudinal observation and decline of neutralizing antibody Microbiol 5, 1598-1607, doi:10.1038/s41564-020-00813-8 (2020).

674 Wajnberg, A. et al. Robust neutralizing antibodies to SARS-CoV-2 infection persist for months. Science, doi:10.1126/science.abd7728 (2020).

22 Zohar, T. \& Alter, G. Dissecting antibody-mediated protection against SARS-CoV-2. Nat Rev Immunol 20, 392-394, doi:10.1038/s41577-020-0359-5 (2020). Dan, J. M. et al., doi:10.1101/2020.11.15.383323 (2020).

678 Corti, D. \& Lanzavecchia, A. Broadly neutralizing antiviral antibodies. Annu Rev Immunol 31, 705-742, doi:10.1146/annurev-immunol-032712-095916 (2013). Mercado, N. B. et al. Single-shot Ad26 vaccine protects against SARS-CoV-2 in rhesus macaques. Nature 586, 583-588, doi:10.1038/s41586-020-2607-z (2020).

682 McMahan, K. et al. Correlates of protection against SARS-CoV-2 in rhesus macaques. Nature, doi:10.1038/s41586-020-03041-6 (2020).

684

27 Zost, S. J. et al. Rapid isolation and profiling of a diverse panel of human monoclonal antibodies targeting the SARS-CoV-2 spike protein. Nat Med 26, 1422-1427, doi:10.1038/s41591-020-0998-x (2020).

686

687

28 Kreer, C. et al. Longitudinal Isolation of Potent Near-Germline SARS-CoV-2Neutralizing Antibodies from COVID-19 Patients. Cell 182, 843-854 e812, doi:10.1016/j.cell.2020.06.044 (2020).

690

29 Robbiani, D. F. et al. Convergent antibody responses to SARS-CoV-2 in convalescent

691

692 individuals. Nature 584, 437-442, doi:10.1038/s41586-020-2456-9 (2020).

693

30 Chen, P. et al. SARS-CoV-2 Neutralizing Antibody LY-CoV555 in Outpatients with Covid-19. N Engl J Med, doi:10.1056/NEJMoa2029849 (2020).

694

31 Weinreich, D. M. et al. REGN-COV2, a Neutralizing Antibody Cocktail, in Outpatients with Covid-19. N Engl J Med, doi:10.1056/NEJMoa2035002 (2020).

695 $\mathrm{Ng}$, D. L. et al. SARS-CoV-2 seroprevalence and neutralizing activity in donor and patient blood. Nat Commun 11, 4698, doi:10.1038/s41467-020-18468-8 (2020). 
2 patient cohort and their implications. MedRxiv, doi:10.1101/2020.03.30.20047365 (2020).

34 Iyer, A. S. et al. Persistence and decay of human antibody responses to the receptor binding domain of SARS-CoV-2 spike protein in COVID-19 patients. Sci Immunol 5, doi:10.1126/sciimmunol.abe0367 (2020).

35 Zeng, C. et al. Neutralizing antibody against SARS-CoV-2 spike in COVID-19 patients, health care workers, and convalescent plasma donors. JCl Insight 5, doi:10.1172/jci.insight.143213 (2020).

36 Chen, $X$. et al. Disease severity dictates SARS-CoV-2-specific neutralizing antibody responses in COVID-19. Signal Transduct Target Ther 5, 180, doi:10.1038/s41392020-00301-9 (2020).

37 Lanzavecchia, A., Fruhwirth, A., Perez, L. \& Corti, D. Antibody-guided vaccine design: identification of protective epitopes. Curr Opin Immunol 41, 62-67, doi:10.1016/j.coi.2016.06.001 (2016).

38 Simek, M. D. et al. Human immunodeficiency virus type 1 elite neutralizers: individuals with broad and potent neutralizing activity identified by using a highthroughput neutralization assay together with an analytical selection algorithm. $J$ Virol 83, 7337-7348, doi:10.1128/JVI.00110-09 (2009).

39 Walker, L. M. \& Burton, D. R. Passive immunotherapy of viral infections: 'superantibodies' enter the fray. Nat Rev Immunol 18, 297-308, doi:10.1038/nri.2017.148 (2018).

40 Hadfield, J. et al. Nextstrain: real-time tracking of pathogen evolution. Bioinformatics 34, 4121-4123, doi:10.1093/bioinformatics/bty407 (2018).

41 Murin, C. D., Wilson, I. A. \& Ward, A. B. Antibody responses to viral infections: a structural perspective across three different enveloped viruses. Nat Microbiol 4, 734747, doi:10.1038/s41564-019-0392-y (2019).

42 Garcia-Beltran, W. F. et al. COVID-19 neutralizing antibodies predict disease severity and survival. medRxiv, doi:10.1101/2020.10.15.20213512 (2020).

43 Roltgen, K. et al. Defining the features and duration of antibody responses to SARSCoV-2 infection associated with disease severity and outcome. Sci Immunol 5, doi:10.1126/sciimmunol.abe0240 (2020).

44 Suthar, M. S. et al. Rapid Generation of Neutralizing Antibody Responses in COVID-19 Patients. Cell Rep Med 1, 100040, doi:10.1016/j.xcrm.2020.100040 (2020).

45 Luchsinger, L. L. et al. Serological Assays Estimate Highly Variable SARS-CoV-2 Neutralizing Antibody Activity in Recovered COVID-19 Patients. J Clin Microbiol 58, doi:10.1128/JCM.02005-20 (2020).

46 Oran, D. P. \& Topol, E. J. Prevalence of Asymptomatic SARS-CoV-2 Infection : A Narrative Review. Ann Intern Med 173, 362-367, doi:10.7326/M20-3012 (2020).

47 Andreano, E. et al. SARS-CoV-2 escape in vitro from a highly neutralizing COVID-19 convalescent plasma. bioRxiv, doi:10.1101/2020.12.28.424451 (2020).

48 Tegally, $\mathrm{H}$. et al. Emergence and rapid spread of a new severe acute respiratory syndrome-related coronavirus 2 (SARS-CoV-2) lineage with multiple spike mutations in South Africa. MedRxiv, doi:10.1101/2020.12.21.20248640 (2020).

49 Thomson, E. C. et al. The circulating SARS-CoV-2 spike variant N439K maintains fitness while evading antibody-mediated immunity. BioRxiv, doi:10.1101/2020.11.04.355842 (2020).

50 Jackson, L. A. et al. An mRNA Vaccine against SARS-CoV-2 - Preliminary Report. $N$ Engl J Med 383, 1920-1931, doi:10.1056/NEJMoa2022483 (2020). 
51 Sasaki, S. et al. Limited efficacy of inactivated influenza vaccine in elderly individuals is associated with decreased production of vaccine-specific antibodies. J Clin Invest 121, 3109-3119, doi:10.1172/JCl57834 (2011).

52 Rogers, T. F. et al. Isolation of potent SARS-CoV-2 neutralizing antibodies and protection from disease in a small animal model. Science 369, 956-963, doi:10.1126/science.abc7520 (2020).

Lv, Z. et al. Structural basis for neutralization of SARS-CoV-2 and SARS-CoV by a potent therapeutic antibody. Science 369, 1505-1509, doi:10.1126/science.abc5881 (2020).

756

54 Prevost, J. et al. Cross-Sectional Evaluation of Humoral Responses against SARS-CoV2 Spike. Cell Rep Med 1, 100126, doi:10.1016/j.xcrm.2020.100126 (2020).

Korber, B. et al. Tracking Changes in SARS-CoV-2 Spike: Evidence that D614G Increases Infectivity of the COVID-19 Virus. Cell 182, 812-827 e819, doi:10.1016/j.cell.2020.06.043 (2020).

761

56 Weissman, D. et al. D614G Spike Mutation Increases SARS CoV-2 Susceptibility to Neutralization. Cell Host Microbe, doi:10.1016/j.chom.2020.11.012 (2020). Amanna, I. J., Carlson, N. E. \& Slifka, M. K. Duration of humoral immunity to common viral and vaccine antigens. $N$ Engl J Med 357, 1903-1915, doi:10.1056/NEJMoa066092 (2007). Edridge, A. W. D. et al. Seasonal coronavirus protective immunity is short-lasting. Nat Med 26, 1691-1693, doi:10.1038/s41591-020-1083-1 (2020). Huang, A. T. et al. A systematic review of antibody mediated immunity to coronaviruses: kinetics, correlates of protection, and association with severity. Nat Commun 11, 4704, doi:10.1038/s41467-020-18450-4 (2020).

Cao, W. C., Liu, W., Zhang, P. H., Zhang, F. \& Richardus, J. H. Disappearance of antibodies to SARS-associated coronavirus after recovery. $N$ Engl J Med 357, 11621163, doi:10.1056/NEJMc070348 (2007).

61 Klingler, J. et al. Role of IgM and IgA Antibodies in the Neutralization of SARS-CoV-2. medRxiv, doi:10.1101/2020.08.18.20177303 (2020).

62 Krammer, F. SARS-CoV-2 vaccines in development. Nature 586, 516-527, doi:10.1038/s41586-020-2798-3 (2020).

63 Crawford, K. H. D. et al. Protocol and Reagents for Pseudotyping Lentiviral Particles with SARS-CoV-2 Spike Protein for Neutralization Assays. Viruses 12, doi:10.3390/v12050513 (2020).

Kärber, G. Beitrag zur kollektiven Behandlung pharmakologischer Reihenversuche. Naunyn-Schmiedebergs Archiv für Experimentelle Pathologie und Pharmakologie 162, 480-483, doi:10.1007/bf01863914 (1931).

788

Spearman, C. The Method of 'Right and Wrong Cases' ('Constant Stimuli') without Gauss's Formulae. British Journal of Psychology, 1904-1920 2, 227-242, doi:10.1111/j.2044-8295.1908.tb00176.x (1908). Journal of Open Source Software 3, doi:10.21105/joss.00772 (2018). 
bioRxiv preprint doi: https://doi.org/10.1101/2021.01.26.428207; this version posted January 26, 2021. The copyright holder for this preprint (which was not certified by peer review) is the author/funder. All rights reserved. No reuse allowed without permission.

\section{Figure 1}

a SARS-CoV-2 + Study visit 1

Study visit 2

Study visit 3

Study visit 4

Total visits

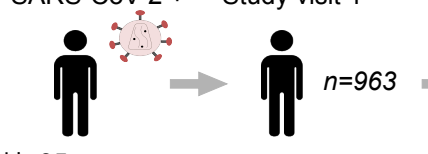

이 $n=616$

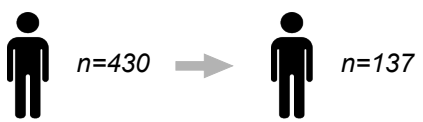

$n=2,146$

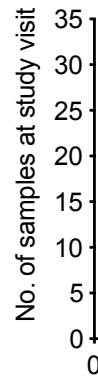

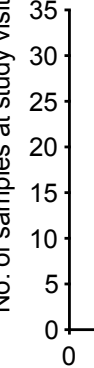

\section{b}

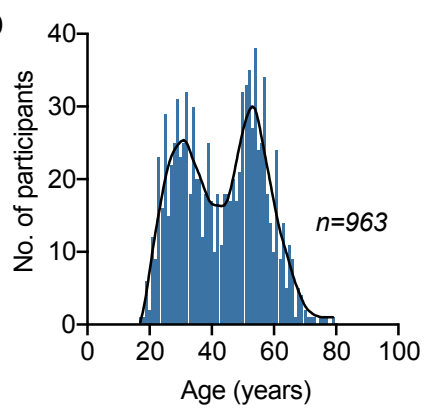

C

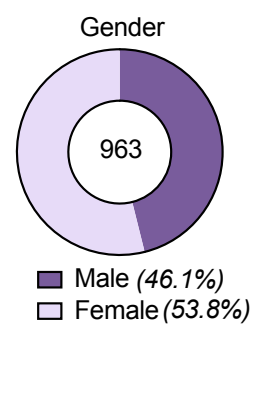

Visit 1

Visit 2

Visit 3

Visit 4

Figure 1: SARS-CoV-2 recovered cohort and study design

a, Illustration depicting study timeline and number of individuals analyzed at each study visit. Graph represents sample collection time for participants in weeks since disease onset (symptom onset date or positive PCR date). b, age distribution of the cohort c, gender distribution, presence of pre-conditions and disease severity. 
bioRxiv preprint doi: https://doi.org/10.1101/2021.01.26.428207; this version posted January 26, 2021. The copyright holder for this preprint (which was not certified by peer review) is the author/funder. All rights reserved. No reuse allowed without permission.

\section{Figure 2}

a Serum Neutralization
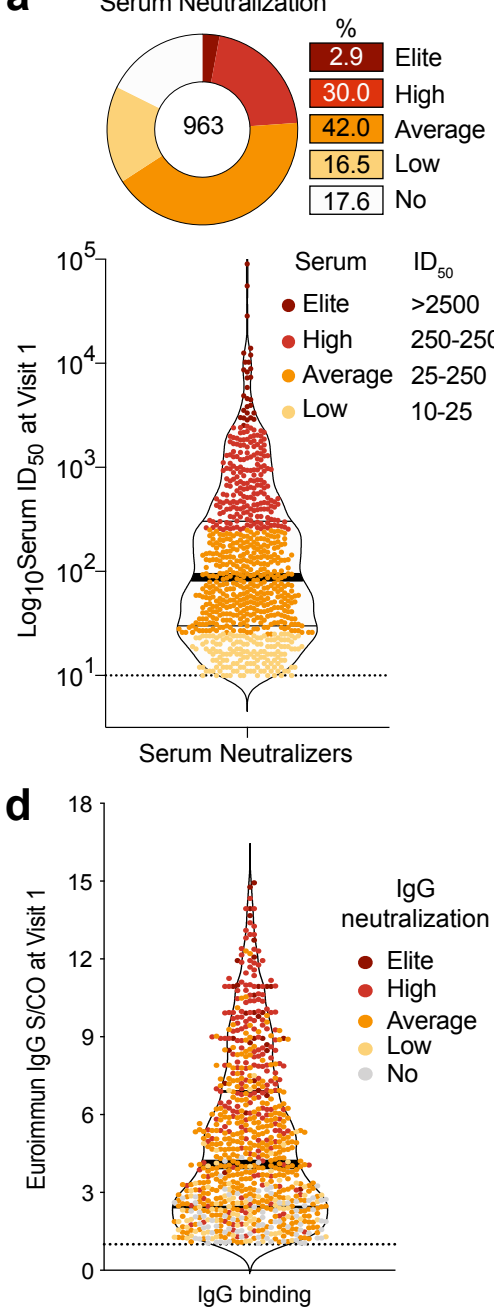

g

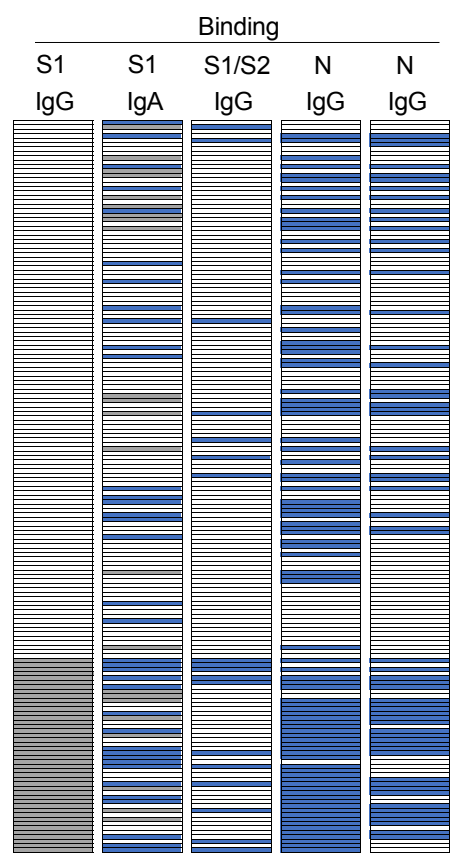

Euroimmun Diasorin Roche Abbott

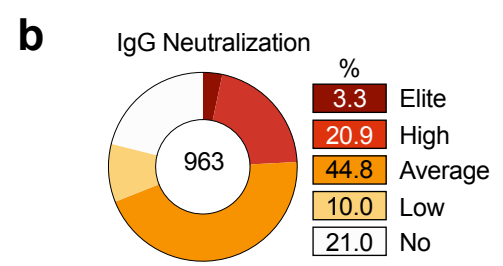

C IgG vs. Serum Neutralization
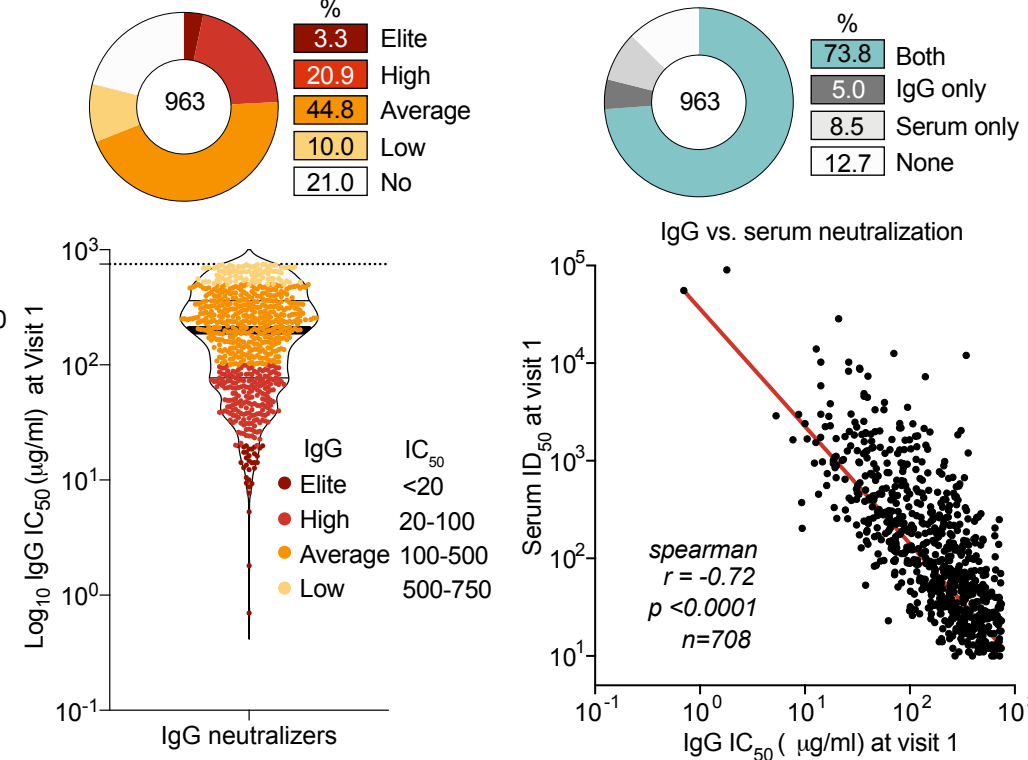

IgG vs. serum neutralization

e

Euroimmun IgG ELISA

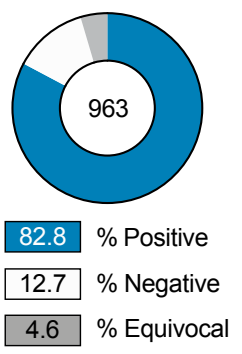

$\mathrm{IC}_{50}$

$<20$

20-100

$500-750$

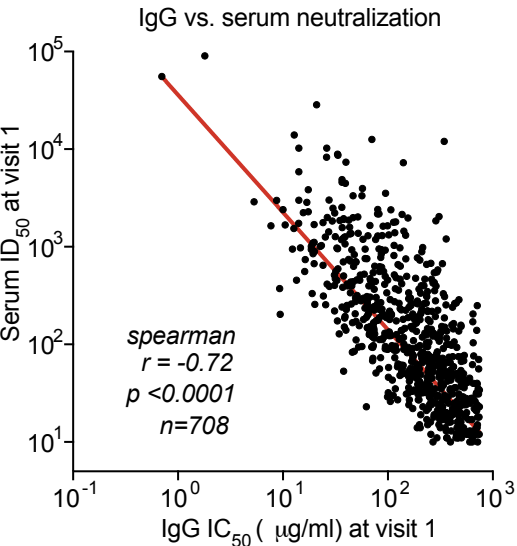

f

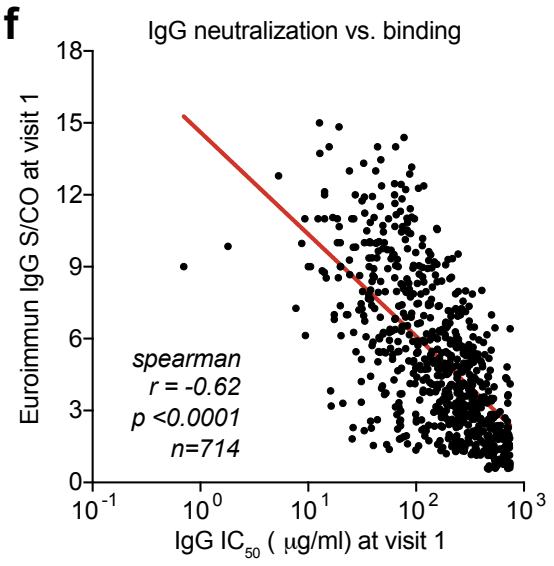

Neutralization

Serum Serum IgG

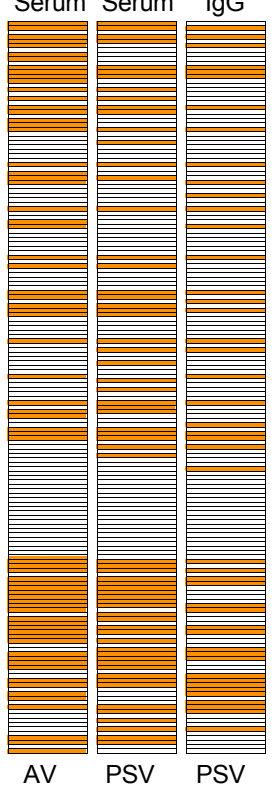

h

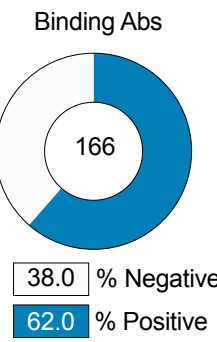

Neutralizing Abs

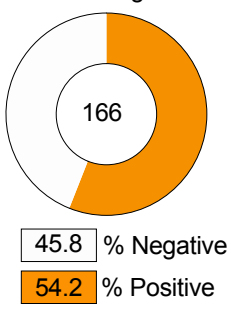

i

Anti-SARS-CoV-2 Abs

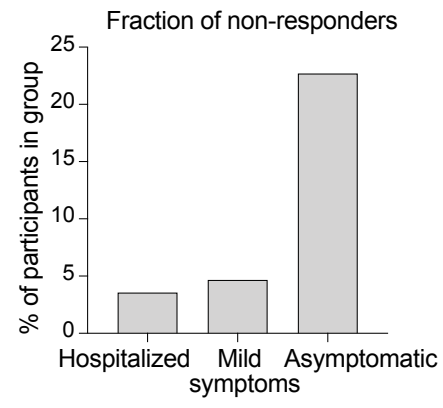

$5.6 \%$ Negative

$94.4 \%$ Positive

Hospitalized Mild Asymptomatic

Figure 2: Neutralizing antibody response after recovery from SARS-CoV-2 infection

a, pie chart illustrating fraction of serum neutralizers against Wu01 pseudovirus at study visit 1 . Violin plot depicts serum ID50 values for the neutralizers $(n=793)$, categorized based on serum ID50 titers. Dotted line represents the LOD (10-fold dilution) of the assay. b, pie chart depicting the fraction of IgG neutralization against Wu01 pseudovirus at study visit 1 . Violin plot depicts IgG IC50 values for the neutralizers $(n=760)$, categorized based on IgG IC50. Dotted line represents the LOD $(750 \mu \mathrm{g} / \mathrm{ml})$ of the assay. c, pie chart comparing fraction of samples with neutralization at serum and/or IgG level. Spearman correlation plot between serum ID50 and IgG IC50 values at study visit 1 . d, violin plot of Euroimmun ELISA signal over cut-off $(\mathrm{S} / \mathrm{CO})$ ratios for anti-spike IgG. Dotted line represents LOD $(\mathrm{S} / \mathrm{CO}=1.1)$ of the assay. e, pie charts illustrating fraction of anti-spike IgG reactive individuals in the Euroimmun ELISA. $\mathbf{f}$, spearman correlation between Euroimmun IgG S/CO and $\operatorname{lgG}$ IC50 at study visit 1 . g, plot depicting binding against spike, Nucleocapsid $(\mathrm{N})$ and neutralizing response against authentic virus (AV) and Wu01 pseudovirus (PSV) of the IgG negative fraction $(n=166)$ with each row representing 1 individual. $h$, pie charts showing total fraction of individuals with binding or neutralizing activity in the IgG-fraction from $\mathbf{g}$. $\mathbf{i}$, pie chart representing total combined binding and NAb response in the cohort $(n=963)$ and bar graph of the Ab-negative individuals based on disease severity. LOD, limit of detection 
bioRxiv preprint doi: https://doi.org/10.1101/2021.01.26.428207; this version posted January 26, 2021. The copyright holder for this preprint (which was not certified by peer review) is the author/funder. All rights reserved. No reuse allowed without permission.

\section{Figure 3}

a

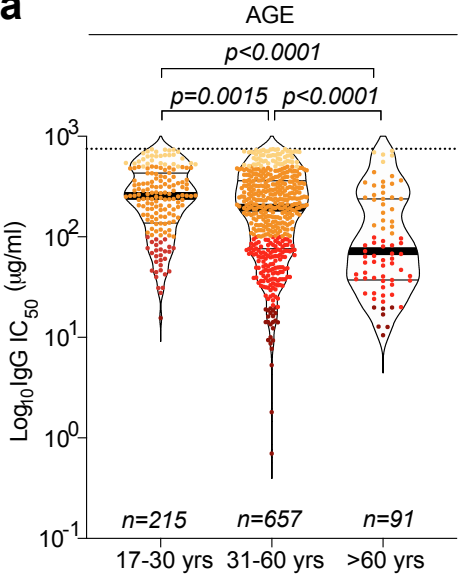

\section{5}

52.5

44.6

\begin{tabular}{|l|l|}
\hline 13.5 & 9.3 \\
\hline \hline 19.5 & 22.0 \\
\hline
\end{tabular}

9.3

\begin{tabular}{|c|}
\hline 7.7 \\
\hline 42.8 \\
\hline 26.4 \\
\hline 5.5 \\
\hline \hline 17.6 \\
\hline
\end{tabular}
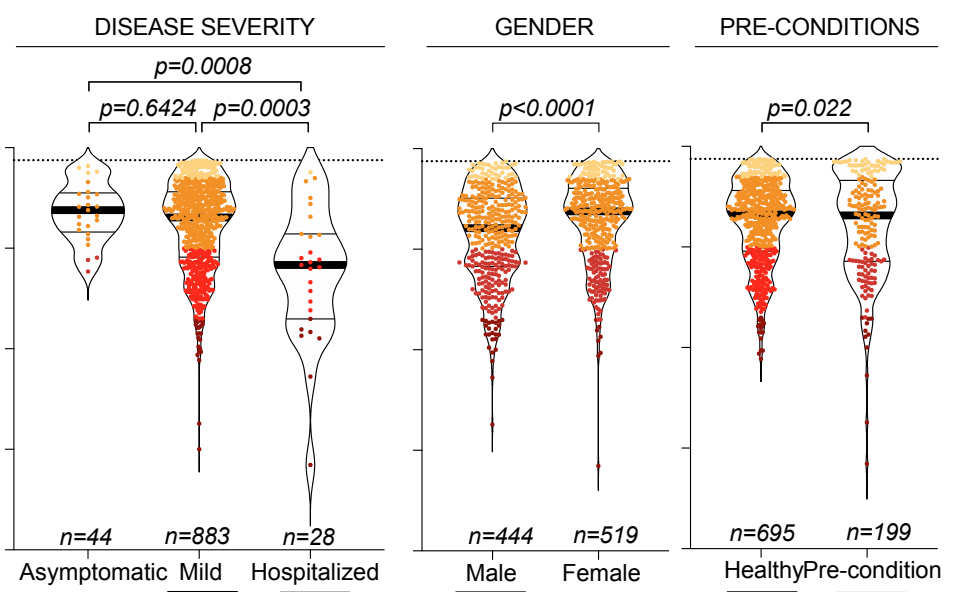

- Elite $<20 \mu \mathrm{g} / \mathrm{ml}$ - Average $100-500 \mu \mathrm{g} / \mathrm{ml}$

- High $20-100 \mu \mathrm{g} / \mathrm{ml}$ - Low $500-750 \mu \mathrm{g} / \mathrm{ml}$

\begin{tabular}{|c|c|c|}
\hline 0.0 & 2.8 & 25.0 \\
\hline 6.8 & 21.0 & 39.2 \\
\hline 40.9 & 45.3 & 28.6 \\
\hline 9.1 & 10.2 & 3.6 \\
\hline 43.2 & 20.7 & 3.6 \\
\hline
\end{tabular}

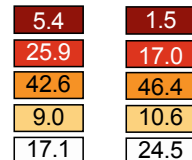

\begin{tabular}{|c|c|}
\hline 2.5 & 5.5 \\
\hline$\overline{19.1}$ & 24.6 \\
\hline$\overline{46.5}$ & $\overline{41.2}$ \\
\hline 10.2 & 12.6 \\
\hline 21.7 & \\
\hline
\end{tabular}

b

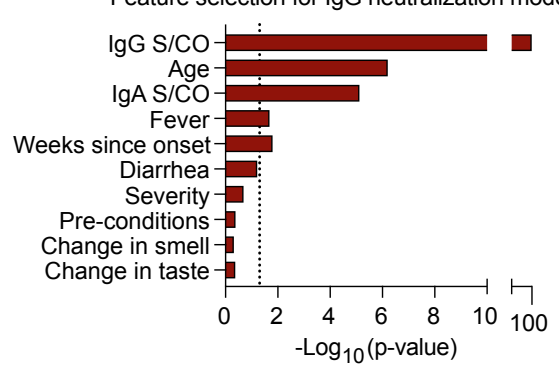

IgG neutralization model: Adjusted $\mathrm{R}^{2}=0.461$

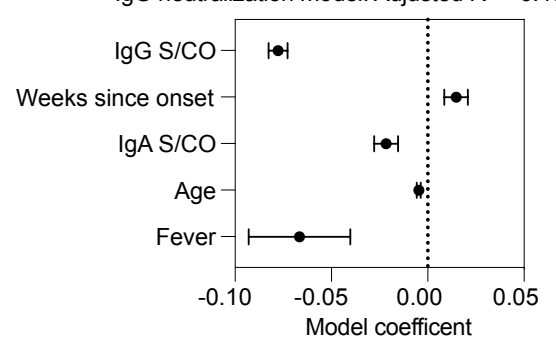

\% Elite Neutralization $\square \%$ Average Neutralization $\square$ \% High Neutralization $\square$ \% Low Neutralization

$\square$ No Neutralization

C

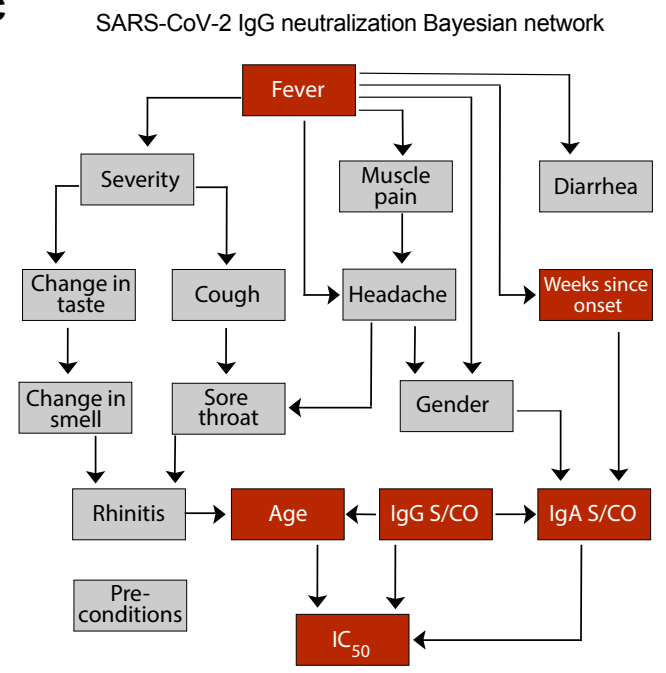

Figure 3: Correlates of neutralizing activity against SARS-CoV-2

a, violin plots depicting IgG neutralization IC50 values at study visit 1 against Wu01 pseudovirus, subdivided based on age, disease severity, gender and pre-conditions. Dotted line represents the limit of detection $(750 \mu \mathrm{g} / \mathrm{ml})$ of the assay. Statistical analysis was performed Kruskal-Wallis and Mann-Whitney tests. b, multiple linear regression model for predicting IgG IC50 using the features: Euroimmun S/CO, gender, age, disease severity, pre-conditions, weeks since infection and the 9 reported symptoms. Plot below depicts model coefficients to study the goodness of fit of the final IC50 prediction model. c, Bayesian network of the features predicting IgG IC50 are plotted using the bnlearn R package. The graph connects the features which are predictive of each other with IgG IC50 as sink. 
bioRxiv preprint doi: https://doi.org/10.1101/2021.01.26.428207; this version posted January 26, 2021. The copyright holder for this

preprint (which was not certified by peer review) is the author/funder. All rights reserved. No reuse allowed without permission.

\section{Figure 4}

a

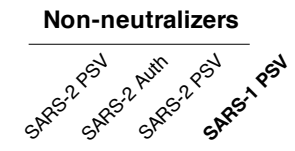

Patient IC50 IC100 ID50 IC50 ID\# $\mu \mathrm{g} / \mathrm{ml} \quad \mu \mathrm{g} / \mathrm{ml}$ titer $\mu \mathrm{g} / \mathrm{ml}$ R016 $>7$\begin{tabular}{c|c|c|c|}
$>750$ & 200 & $<10$ & $>750$ \\
\hline
\end{tabular} \begin{tabular}{|l|c|c|c|c|}
\hline R064 & $>750$ & 1000 & $<10$ & $>750$ \\
\hline
\end{tabular} \begin{tabular}{ll|l|l|l|l|} 
R135 & $>750$ & 1000 & $<10$ & $>750$ \\
\hline
\end{tabular} R177 $>750>1000 \quad<10$ R223 $>750>1000<10$ R315 $>750 \quad 1000<10$ R380 $>750>1000<10$ \begin{tabular}{ll|l|l|l|} 
R395 & $>750$ & 1000 & 14 \\
\hline
\end{tabular} R400 $>>750>1000<10$ \begin{tabular}{ll|l|l|l|} 
R408 & $>750$ & $>1000$ & $<10$
\end{tabular} \begin{tabular}{l|l|l|l|}
$R 856$ & $>750$ & 1000 & 11 \\
\hline
\end{tabular} \begin{tabular}{ll|l|r|c|} 
R506 & $>750$ & $>1000$ & $<10$ \\
\hline
\end{tabular} R588 $>750>1000<10$ \begin{tabular}{|l|c|c|c|} 
R776 & $>750$ & 1000 & $<10$ \\
\hline
\end{tabular} \begin{tabular}{|l|l|l|l|}
$\mathrm{R} 814$ & $>750$ & $>1000$ & $<10$ \\
\hline
\end{tabular}

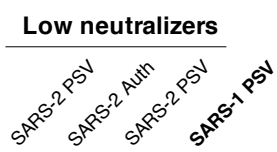

Patient IC50 IC100 ID50 IC50 ID\# $\mu \mathrm{g} / \mathrm{ml} \quad \mu \mathrm{g} / \mathrm{ml}$ titer $\mu \mathrm{g} / \mathrm{m}$

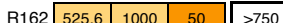
\begin{tabular}{|l|l|l|l||l|}
\hline R129 & 537.0 & $>1000$ & 40 & $>750$ \\
\hline
\end{tabular} \begin{tabular}{l|l|l|l|l|} 
R753 & 562.8 & 1000 & 12 & $>750$ \\
\hline
\end{tabular} \begin{tabular}{|l|l|l|l|l}
\hline R452 & 555.6 & 1000 & 24 \\
\hline
\end{tabular} \begin{tabular}{l|l|l|l|} 
R217 & 590.5 & 1000 & 12 \\
\hline
\end{tabular} \begin{tabular}{|l|l|l|l|} 
R807 & 601.9 & 200 & 45 \\
\hline
\end{tabular} \begin{tabular}{l|l|l|l|l|} 
R007 & 631.9 & 1000 & 17
\end{tabular} \begin{tabular}{l|c|c|c|} 
R234 & 645.6 & 1000 & 170 \\
\hline
\end{tabular} \begin{tabular}{|l|l|l|l|} 
R211 & 657.0 & $>1000$ & 27 \\
\hline
\end{tabular} \begin{tabular}{l|l|l|l|l|} 
R457 & 679.4 & 200 & 26 \\
\hline
\end{tabular} \begin{tabular}{l|c|c|c|} 
R456 & 696.8 & 1000 & 12 \\
\hline
\end{tabular} \begin{tabular}{|l|l|l|l|} 
R369 & 703.9 & 1000 & 139 \\
\hline
\end{tabular} \begin{tabular}{|l|l|l|l|} 
R296 & 707.7 & 1000 & 39 \\
\hline
\end{tabular} \begin{tabular}{l|l|l|l|l|} 
R364 & 707.7 & 200 & 40 \\
\hline
\end{tabular} \begin{tabular}{l|c|c|c|} 
R680 & 740.0 & 1000 & 18 \\
\hline
\end{tabular}
Average neutralizers

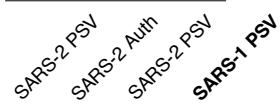

Patient IC50 IC $100 \quad$ ID50 IC50 ID\# $\mu \mathrm{g} / \mathrm{ml} \mu \mathrm{g} / \mathrm{ml}$ titer $\mu \mathrm{g} / \mathrm{ml}$ \begin{tabular}{ll|l|l|l|} 
R154 & 101.9 & 200 & 1322 & $>750$ \\
\hline
\end{tabular} \begin{tabular}{|l|l|l|l||l|} 
R320 & 102.9 & 200 & 123 & $>750$ \\
\hline
\end{tabular} \begin{tabular}{l|l|l|l||l|} 
R823 & 127.9 & 40 & 263 & $>750$ \\
\hline
\end{tabular} \begin{tabular}{|l|c|c|c|c|}
\hline R722 & 140.7 & 200 & 118 & $>750$ \\
\hline
\end{tabular}

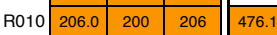
\begin{tabular}{|l|l|l|l|} 
R432 & 185.0 & 200 & 51 \\
\hline
\end{tabular} \begin{tabular}{l|l|c|c|} 
R679 & 229.2 & 1000 & $<10$ \\
\hline
\end{tabular} \begin{tabular}{|l|l|l|l|l|}
$R$ & 2474 & 248.1 & 1000 & $<10$ \\
\hline
\end{tabular} \begin{tabular}{l|l|l|l|} 
R675 & 278.9 & 1000 & 355 \\
\hline
\end{tabular} \begin{tabular}{ll|l|l|l|} 
R245 & 404.6 & 1000 & 98 \\
\hline
\end{tabular} \begin{tabular}{ll|l|l|l|} 
R649 & 318.8 & 200 & 56 \\
\hline
\end{tabular} \begin{tabular}{l|l|l|l|} 
R101 & 368.7 & 1000 & 42 \\
\hline
\end{tabular} \begin{tabular}{|l|l|l|l|}
\hline R709 & 394.4 & 200 & 35 \\
\hline
\end{tabular} \begin{tabular}{|l|c|c|c|}
$R 751$ & 442.4 & 1000 & 36 \\
\hline
\end{tabular} \begin{tabular}{c|c|c|c|c|} 
R751 & 442.4 & 1000 & 36 \\
\cline { 3 - 4 } & 493.0 & 200 & 15 \\
\hline
\end{tabular}

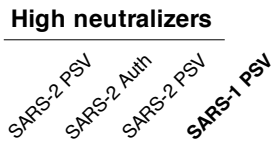

Patient IC50 IC100 ID50 IC50 ID\# $\mu \mathrm{g} / \mathrm{ml} \mu \mathrm{g} / \mathrm{ml}$ titer $\mu \mathrm{g} / \mathrm{m}$ \begin{tabular}{l|l|l|l|l|} 
R579 & 27.7 & 200 & 392 & 435.8 \\
\hline
\end{tabular} \begin{tabular}{|l|l|l|l||r|} 
R849 & 31.0 & 120 & 220 & 5.1 \\
\hline
\end{tabular} \begin{tabular}{|l|l|l|l|l|} 
R195 & 31.2 & 200 & 2216 & 129.1 \\
\hline
\end{tabular} \begin{tabular}{|l|l|l|l|l|l|} 
R561 & 38.4 & 120 & 151 & 212.4 \\
\hline
\end{tabular} \begin{tabular}{|l|l|l|l|l|l|} 
R759 & 47.9 & 120 & 830 & 226.8 \\
\hline
\end{tabular} \begin{tabular}{l|l|l|l|l|l|} 
R227 & 52.2 & 1000 & 1377 & $>750$ \\
\hline
\end{tabular} \begin{tabular}{l|l|l|l|l|} 
R136 & 63.1 & 200 & 309 & $>750$ \\
\hline
\end{tabular} \begin{tabular}{|l|c|c|c||c|} 
R824 & 64.7 & 40 & $<10$ & 443.0 \\
\hline
\end{tabular} \begin{tabular}{|l|c|c|c||c|}
\hline R189 & 70.0 & $>1000$ & 94 & 728.5 \\
\hline
\end{tabular} \begin{tabular}{c|c|c|c|c|} 
R702 & 79.7 & 200 & 2169 & $>750$ \\
\hline
\end{tabular} \begin{tabular}{|l|l|l|l|l|} 
R501 & 80.0 & 40 & 1288 & 202.3 \\
\hline
\end{tabular} \begin{tabular}{ll|l|l|l|l|} 
R205 & 83.1 & 200 & 624 & $>750$ \\
\hline
\end{tabular} \begin{tabular}{l|l|l|l|l|l|l|}
$R 851$ & 88.3 & 40 & 1302 & $>750$ \\
\hline
\end{tabular} \begin{tabular}{|l|l|l|l|}
\cline { 2 - 4 } & $>750$ \\
\hline & 982 & 200 & 29 \\
\hline
\end{tabular} \begin{tabular}{c|c|c|c||c|} 
R301 & 99.2 & 200 & 29 & $>750$ \\
\cline { 2 - 5 } R102 & 99.3 & 40 & 1641 & $>750$ \\
\hline
\end{tabular}
Elite neutralizers

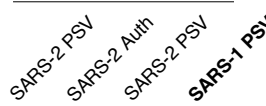

Patient IC50 IC100 ID50 IC50 D\# $\mu \mathrm{g} / \mathrm{ml} \mu \mathrm{g} / \mathrm{ml}$ titer $\mu \mathrm{g} / \mathrm{m}$ \begin{tabular}{|l|l|l|l|l|} 
R568 & 0.7 & 8 & 55379 & 12.1 \\
\hline
\end{tabular} \begin{tabular}{|l|l|l|l|l|} 
R616 & 1.8 & 24 & 90092 & 33.1 \\
\hline
\end{tabular} \begin{tabular}{l|l|l|l|l|l|} 
R488 & 7.7 & 40 & 1640 & 189.6 \\
\hline
\end{tabular} \begin{tabular}{l|l|l|l|l|l|l|} 
R259 & 8.7 & 120 & 2984 & 61 \\
\hline
\end{tabular} \begin{tabular}{|l|c|c|c|c|} 
R200 & 9.3 & 104 & 373 & 391.7 \\
\hline
\end{tabular} \begin{tabular}{l|l|l|l|l|} 
R924 & 9.4 & 120 & 203 & 634.9 \\
\hline
\end{tabular} \begin{tabular}{l|l|l|l|l|} 
R552 & 10.5 & 120 & 1674 & 27.4 \\
\hline
\end{tabular} \begin{tabular}{l|l|l|l|l|l|} 
R207 & 12.3 & 24 & 948 & 55.0 \\
\hline
\end{tabular} \begin{tabular}{|l|l|l|l|l|} 
R121 & 14.1 & 24 & 1741 & 47.9 \\
\hline
\end{tabular} \begin{tabular}{|l|l|l|l|l|} 
R040 & 14.2 & 24 & 5858 & 22.4 \\
\hline
\end{tabular} \begin{tabular}{l|l|l|l|l|} 
R339 & 14.7 & 40 & 975 & 40.4 \\
\hline
\end{tabular} \begin{tabular}{ll|l|l|l|l|} 
R441 & 15.6 & 40 & 2239 & 219.6 \\
\hline
\end{tabular} \begin{tabular}{c|c|c|c|c|} 
R410 & 19.8 & 40 & 1690 & 33.7 \\
\hline
\end{tabular}

\section{\begin{tabular}{llll|l|l|}
$<20$ & $20-100$ & $100-500$ & $500-750$ & $>750$ \\
\hline
\end{tabular} \\ $\mathrm{gG} \mathrm{IC}_{\mathrm{s0}}(\mu \mathrm{g} / \mathrm{ml})$ against Pseudovirus (PSV) \\ \begin{tabular}{|l|l|l|l|l|}
\hline$<20$ & $20-100$ & $100-500$ & $500-1000$ & $>1000$ \\
\hline
\end{tabular} $\lg \mathrm{IC}_{100}(\mu \mathrm{g} / \mathrm{ml})$ against Authentic virus (Auth)}

\section{\begin{tabular}{lll|l|l|}
$>2500$ & $250-2500$ & $25-250$ & $10-25$ & $<10$ \\
\hline
\end{tabular}}

b

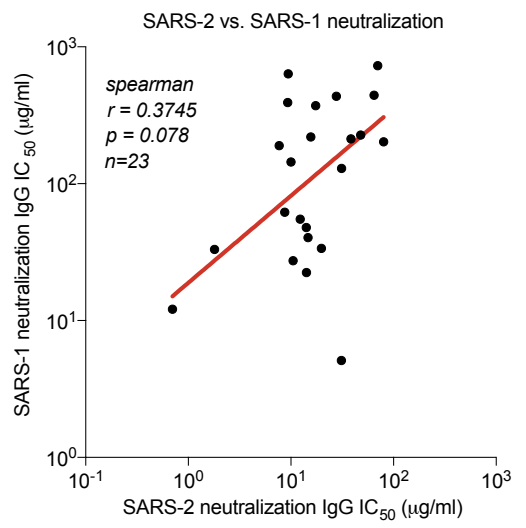

C

\begin{tabular}{ccccc}
$\begin{array}{c}\text { SARS-2-S } \\
\text { Virus name }\end{array}$ & $\begin{array}{c}\text { GISAID } \\
\text { identifier }\end{array}$ & $\begin{array}{c}\text { Region of origin } \\
\text { of stran }\end{array}$ & $\begin{array}{c}\text { A.A residue } \\
\text { mutation on } \\
\text { spike }\end{array}$ & $\begin{array}{c}\text { Location of } \\
\text { mutation on } \\
\text { spike }\end{array}$ \\
\hline Wu01 & EPI_ISL_40671 & Wuhan, China & - & - \\
\hline BavP1 & EPI_ISL_406862 & Bavaria, Germany & D614G & S1 \\
\hline ARA36 & EPI_ISL_418432 & Lyon, France & D936Y & S2; Heptad Repeat \\
\hline DRC94 & EPI_ISL_417947 & Kinshasa, Africa & $\begin{array}{c}\text { D614G } \\
\text { L8211 }\end{array}$ & $\begin{array}{c}\text { S1 and S2 (fusion } \\
\text { peptide) }\end{array}$ \\
\hline CA5 & EPI_ISL_408010 & California, USA & H49Y & $\begin{array}{c}\text { S1; N Terminal } \\
\text { domain }\end{array}$ \\
\hline NRW8 & EPI_ISL_414508 & $\begin{array}{c}\text { Heinsberg, } \\
\text { Germany }\end{array}$ & S254F & $\begin{array}{c}\text { S1; N Terminal } \\
\text { domain }\end{array}$ \\
& & & &
\end{tabular}

d

\begin{tabular}{|c|c|c|c|c|c|c|}
\hline $\begin{array}{l}\text { Patien } \\
\text { ID\# }\end{array}$ & no & & $p^{2 p}$ & & $c^{r^{5}}$ & 5 \\
\hline R568 & 0.7 & 0.3 & 0.4 & 0.5 & 0.7 & 0.5 \\
\hline R616 & 1.8 & 2.0 & 7.8 & 3.1 & 3.9 & 2.1 \\
\hline R488 & 7.7 & 10.8 & 18.0 & 18.6 & 12.5 & 11.1 \\
\hline R259 & 8.7 & 12.7 & 9.8 & 15.5 & 6.0 & 11.2 \\
\hline R200 & 9.3 & 7.8 & 24.7 & 15.0 & 11.2 & 16.6 \\
\hline R924 & 9.4 & 25.3 & 31.2 & 34.1 & 56.8 & 25.1 \\
\hline R627 & 10.0 & 15.6 & 25.2 & 11.2 & 19.6 & 5.1 \\
\hline R552 & 10.5 & 10.8 & 19.2 & 11.4 & 19.2 & 20.6 \\
\hline R207 & 12.3 & 6.8 & 5.9 & 6.3 & 13.8 & 8.0 \\
\hline R121 & 14.1 & 9.5 & 4.9 & 10.6 & 8.6 & 5.2 \\
\hline R040 & 14.2 & 5.7 & 7.0 & 11.0 & 13.4 & 14.2 \\
\hline R339 & 14.7 & 31.7 & 8.4 & 14.4 & 16.9 & 25.0 \\
\hline R441 & 15.6 & 8.7 & 12.6 & 6.1 & 23.6 & 15.3 \\
\hline R270 & 17.4 & 20.5 & 20.7 & 10.0 & 24.4 & 13.6 \\
\hline R410 & 19.8 & 18.2 & 46.5 & 11.3 & 40.9 & 31.4 \\
\hline & $<20$ & $20-10$ & 00 & 50 & -750 & $>750$ \\
\hline
\end{tabular}

Figure 4: Cross-neutralization by SARS-CoV-2 elite neutralizers

a, heat maps visualizing the neutralizing activity of 15 individuals from each neutralization category: Elite-, High-, Average-, Low-, and Non-neutralizers (total $n=75$ ) against SARS-CoV-2-S pseudovirus, SARS-CoV-2 authentic virus and SARS-CoV (SARS-1) pseudovirus, b, Spearman correlation of IgG IC50 against SARS-2-S and SARS-1-S pseudovirus. c, details on the source and type of spike mutations in 6 global strains of SARS-CoV-2 generated and used in this study. d, heat map visualizing the IC50 values of 15 Elite-neutralizers against the 6 SARS-CoV-2 global spike variants from $\mathbf{c}$. 
bioRxiv preprint doi: https://doi.org/10.1101/2021.01.26.428207; this version posted January 26, 2021. The copyright holder for this preprint (which was not certified by peer review) is the author/funder. All rights reserved. No reuse allowed without permission.

\section{Figure 5}

a

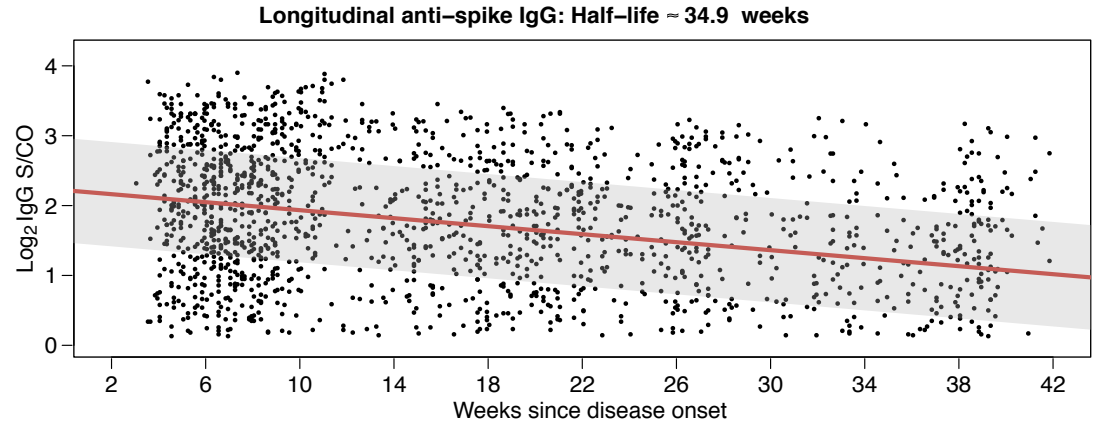

b

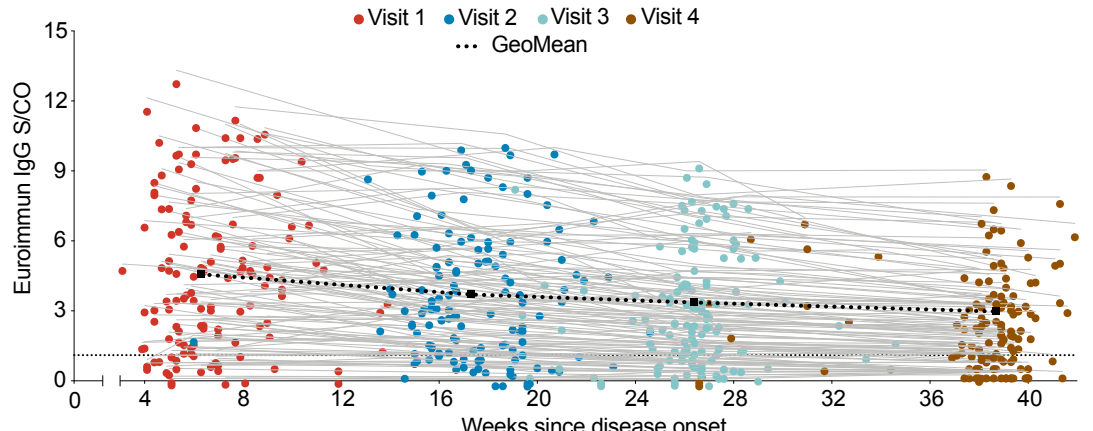

C

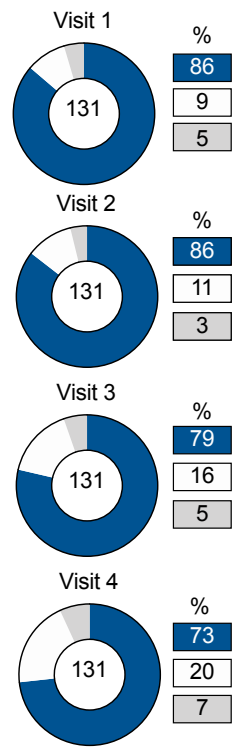

$\operatorname{lgG}$ ELISA

Pos Neg Equi d

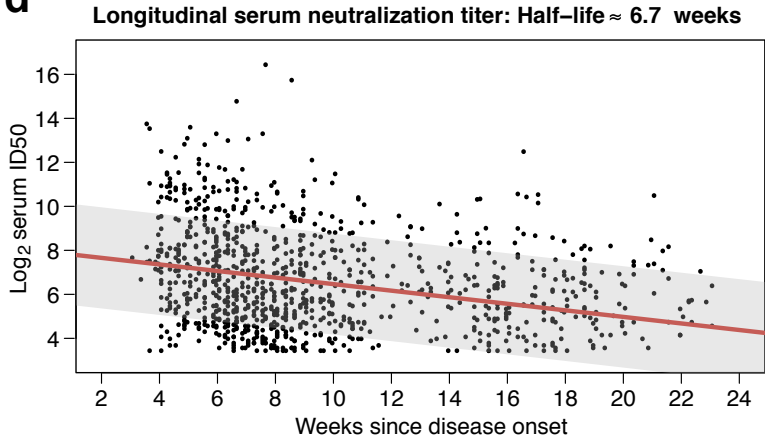

f
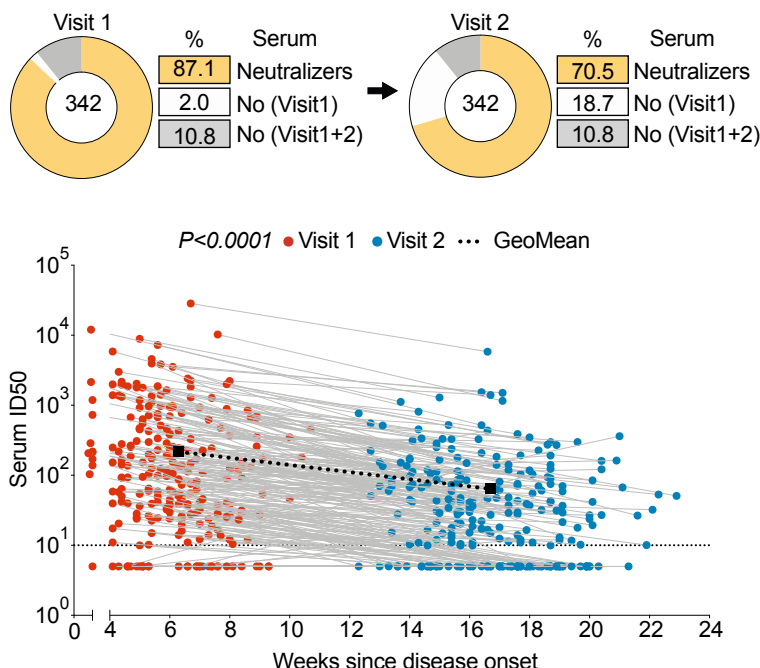

e

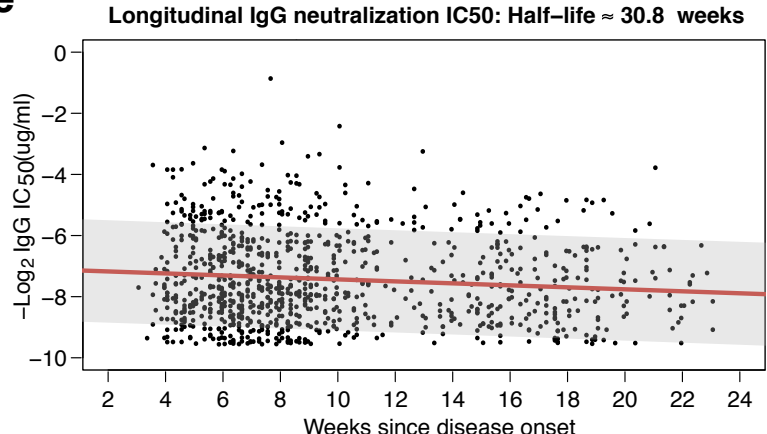

g
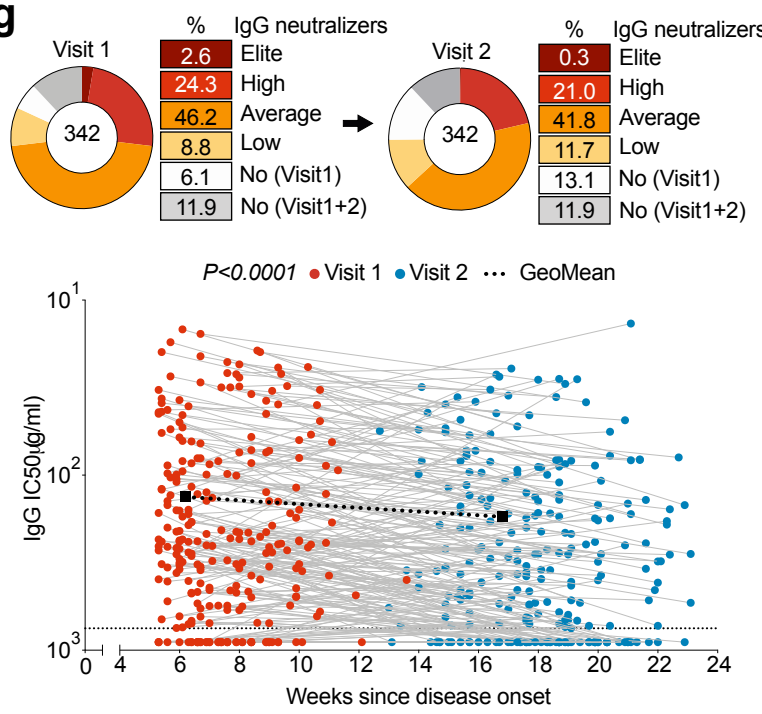

Figure 5: Longitudinal maintenance of anti-SARS-CoV-2 IgG antibody titers

a, IgG ELISA ratios $(n=1,669)$ plotted against weeks since infection for half-life estimate of anti-spike lgG levels using a linear mixed-effects model. $\mathbf{b}$, longitudinal mapping of IgG levels in 131 individuals from visit 1-4. Dot plots illustrate antibody titer against the weeks since infection to study visit 1 (red) and study visit 2 (blue). Geometric mean change shown in black. Dotted lines represent limit of detection (S/CO=1.1 for lgG ELISA). c, pie charts illustrate the change in the fraction of IgG ELISA positive (Pos), Negative (Neg) and Equivocal (Equi) samples ( $n=131$ ) between the study visits. d, serum ID50 values against Wu01 pseudovirus $(n=1,017)$ and $\mathbf{e}, \operatorname{IgG}$ IC50 values against Wu01 pseudovirus ( $n=996)$ plotted against weeks since infection for half-life estimate of the antibody levels using a linear mixed effects model. Longitudinal mapping of serum neutralization (f) and IgG neutralization (g) in 342 individuals at study visit 1 and 2 . Serum and IgG non-neutralizers were assigned values of ID50 $=5$ and IC50=900 for plotting. Dotted lines represent limit of detection (ID50 of 10 and IC50 of $750 \mu \mathrm{g} / \mathrm{ml}$ for serum and IgG neutralization assays). Pie charts illustrate the change in the fraction of serum neutralizers (f) and IgG neutralizers $(\mathbf{g})$ in the samples ( $n=342)$ between the study visits. 